ZRC SAZU, UMETNOSTNOZGODOVINSKI INŠTITUT FRANCETA STELETA

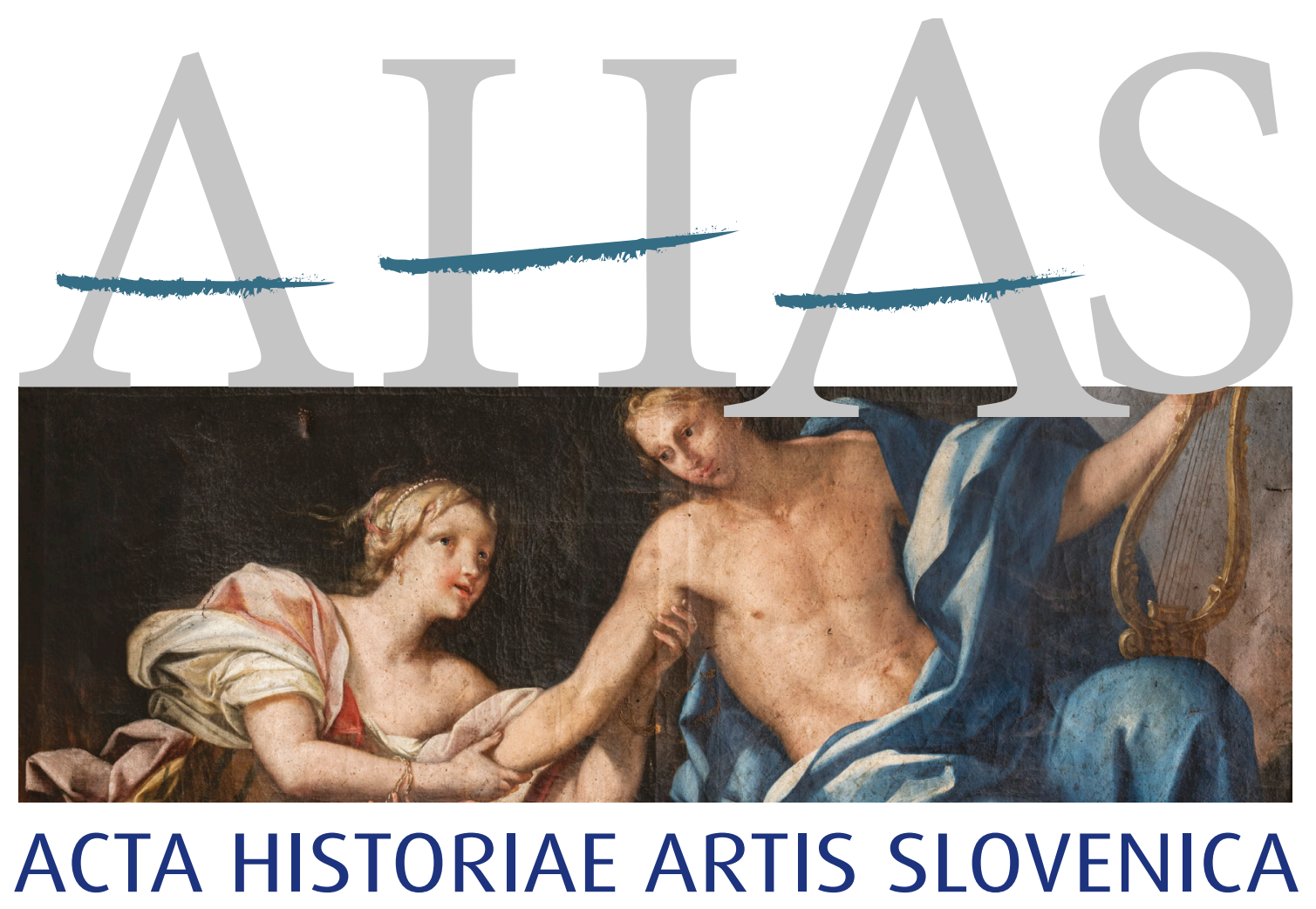

Frančišek Karel Remb in slikarstvo

v habsburških dednih deželah okrog leta 1700

Franz Carl Remp and Painting in the Habsburg Hereditary Lands around 1700

Franz Carl Remp und die Malerei in den habsburgischen Erblanden um 1700

$$
26 \mid 2 \cdot 2021
$$




\section{ACTA HISTORIAE ARTIS SLOVENICA $26 \mid 2 \cdot 2021$}

Frančišek Karel Remb in slikarstvo v habsburških dednih deželah okrog leta 1700

Franz Carl Remp and Painting in the Habsburg Hereditary Lands around 1700

Franz Carl Remp und die Malerei in den habsburgischen Erblanden um 1700 
Acta historiae artis Slovenica, 26/2, 2021

Frančišek Karel Remb in slikarstvo v habsburških dednih deželah okrog leta 1700

Franz Carl Remp and Painting in the Habsburg Hereditary Lands around 1700

Franz Carl Remp und die Malerei in den habsburgischen Erblanden um 1700

Znanstvena revija za umetnostno zgodovino / Scholarly Journal for Art History

ISSN 1408-0419 (tiskana izdaja / print edition) ISSN 2536-4200 (spletna izdaja / web edition)

ISBN 978-961-05-0568-6

Izdajatelj / Issued by

ZRC SAZU, Umetnostnozgodovinski inštitut Franceta Steleta /

ZRC SAZU, France Stele Institute of Art History

Založnik / Publisher

Založba ZRC

Urednika / Edited by

Edgar Lein, Polona Vidmar

Uredniški odbor / Editorial board

Renata Komić Marn, Tina Košak, Katarina Mohar, Mija Oter Gorenčič, Blaž Resman, Helena Seražin

Mednarodni svetovalni odbor / International advisory board

Günter Brucher (Salzburg), Ana María Fernández García (Oviedo), Hellmut Lorenz (Wien),

Milan Pelc (Zagreb), Sergio Tavano (Gorizia-Trieste), Barbara Wisch (New York)

Lektoriranje / Language editing

Oliver Currie, Manuela Dajnko, Andrea Leskovec

Prevodi / Translations

Alan Harvey Cook, Blaž Resman, Nika Vaupotič, Polona Vidmar

Celostni strokovni in jezikovni pregled / Expert and language editing

Blaž Resman

Oblikovna zasnova in prelom / Design and layout

Andrej Furlan

Naslov uredništva / Editorial office address

Acta historiae artis Slovenica

Novi trg 2, p. p. 306, SI -1001 Ljubljana, Slovenija

ahas@zrc-sazu.si; https://ojs.zrc-sazu.si/ahas

Revija je indeksirana v / Journal is indexed in

Scopus, ERIH PLUS, EBSCO Publishing, IBZ, BHA

Letna naročnina / Annual subscription: $35 €$

Posamezna enojna številka / Single issue: $25 €$

Letna naročnina za študente in dijake: $25 €$

Letna naročnina za tujino in ustanove / Annual subscription outside Slovenia, institutions: $48 €$

Naročila sprejema / For orders contact

Založba ZRC

Novi trg 2, p. p. 306, SI-1001, Slovenija

E-pošta / E-mail: zalozba@zrc-sazu.si

AHAS izhaja s podporo Javne agencije za raziskovalno dejavnost Republike Slovenije.

AHAS is published with the support of the Slovenian Research Agency.

(c) 2021, ZRC SAZU, Umetnostnozgodovinski inštitut Franceta Steleta, Založba ZRC, Ljubljana Tisk / Printed by Collegium Graphicum d.o.o., Ljubljana

Naklada / Print run: 400 


\section{VSEBINA \\ Contents}

Edgar Lein, Polona Vidmar

Frančišek Karel Remb in slikarstvo v habsburških dednih deželah okrog leta 1700. Predgovor ...........................5

Franz Carl Remp and Painting in the Habsburg Hereditary Lands around 1700. Preface .....................................7

Franz Carl Remp und die Malerei in den habsburgischen Erblanden um 1700. Vorwort .....................................9

\section{DISSERTATIONES}

Karin Požin

Remp's Ceiling Paintings in the Palais Attems in Graz. From Reproductive Prints to Frescoes

Rembove stropne poslikave v graški palači Attems. Od grafičnih predlog do fresk ...13

Georg Lechner

Franz Carl Remp zwischen Graz und Wien 31

Frančišek Karel Remb med Gradcem in Dunajem 48

Edgar Lein

Preis und Wert der Malerei um 1700. Zu den Kosten von Gemälden in der Steiermark 51

Cena in vrednost slik okrog leta 1700. O stroških za slike na Štajerskem

Renata Komić Marn

Zaplemba - prenos - distribucija. Slike grofa Attemsa iz gradu Slovenska Bistrica $v$ slovenskih javnih zbirkah

Confiscation - Transfer - Distribution. Count Attems' Paintings from

Slovenska Bistrica Castle in Slovenian Public Collections

Polona Vidmar

Emblematische Gratulationsschriften, Stammbäume und Porträts

von Dominik Franz Calin von Marienberg für das Haus Habsburg.

Emblematična voščila, rodovniki in portreti Dominika Frančiška Kalina

von Marienberga za Habsburžane

Ulrich Becker

Weltgeschichte im Wimmelbild. Stephan Kessler und der Entsatz von Wien 1683.

Svetovna zgodovina na »mrgoleči sliki«. Stephan Kessler in Rešitev Dunaja leta 1683 
Andreas Gamerith

Zeit des Experiments. Die Galleria maior des Stiftes Zwettl als Beispiel

für seicenteske Wandmalerei in Niederösterreich.

Čas eksperimentiranja. Galleria maior v samostanu Zwettl

kot primer stenskega slikarstva 17. stoletja v Spodnji Avstriji

\section{Martin Mádl}

The Patterns of the Transformation in Central European Ceiling Painting

around 1700 and Franz Carl Remp in Brežice Castle.

Vzorci transformacije v srednjeevropskem stropnem slikarstvu okrog leta 1700

in Frančišek Karel Remb v brežiškem gradu 


\section{Predgovor}

\section{FranČIŠEK KAREL REMB IN SLIKARSTVO V HABSBURŠKIH DEDNIH DEŽELAH OKROG LETA 1700}

Kljub razmeroma številnim slikam je ostal opus v Radovljici rojenega ter v Gradcu in na Dunaju delujočega slikarja Frančiška Karla Remba (1675-1718) široki javnosti doslej večinoma neznan. Prva in zaenkrat edina razstava Rembovih del je bila od 26. oktobra 1973 do 19. maja 1974 na ogled v Spodnjem Belvederu na Dunaju ter junija 1974 v vogalni sobi Stare galerije muzeja Joanneum v graški Neutorgasse. Razstavni katalog z naslovom Der Barockmaler Franz Carl Remp 1674-1718 vsebuje sedem strani obsegajoč uvod v umetnikovo življenje in delo, kataložni del z dvajsetimi enotami, časovnico in seznam literature.

Georg Lechner se je s Frančiškom Karlom Rembom ukvarjal v okviru svoje leta 2010 na Dunaju obranjene doktorske disertacije. Ko je spomladi 2018 Lechner opozoril, da se jeseni bliža tristota obletnica Rembove smrti, vendar ni niti na Dunaju niti v Gradcu načrtovana kakšna razstava slikarjevih del, smo se odločili za organizacijo simpozija, ki je pod naslovom Slikarji in naročniki. Frančišek Karel Remb in slikarstvo na Štajerskem okrog 1700 potekal 23. novembra 2018 v Laterneng'wölb dvorca Eggenberg. Naslednji dan so si udeleženci pod vodstvom Georga Lechnerja ogledali palačo Attems in pod vodstvom Paula Schusterja reprezentativne prostore dvorca Eggenberg. Simpozij so podprli univerzi v Gradcu in Mariboru ter Znanstvenoraziskovalni center Slovenske akademije znanosti in umetnosti, Umetnostnozgodovinski inštitut Franceta Steleta. Bil je del bilateralnega projekta BI SLO-AT/16-17-18: Umetnostni naročniki kot nosilci deželne identitete. Vloga in pomen naročnikov za gradnjo in opremo plemiških rezidenc in romarskih središč na Štajerskem, ki sta ga financirala Javna agencija za raziskovalno dejavnost Republike Slovenije in Österreichischer Austauschdienst, ter temeljnega raziskovalnega projekta J6-7410: Umetnostna reprezentacija plemstva. Naročništvo na Štajerskem $v$ zgodnjem novem veku (2016-2018), ki ga je financirala Javna agencija za raziskovalno dejavnost Republike Slovenije.

Simpozij so otvorili Georg Lechner s temeljnim prispevkom o Frančišku Karlu Rembu med Gradcem in Dunajem (Franz Carl Remp zwischen Graz und Wien), Christine Rabensteiner, ki je predstavila dela priseljenih in na Štajerskem rojenih baročnih slikarjev v depojih graške Stare galerije (Werke immigrierter und gebürtiger steirischer Barockmaler. Ein Blick in das Depot der Alten Galerie), ter Karin Požin s študijo o Rembovih stropnih poslikavah v palači Attems v Gradcu in likovnih virih zanje (Case Study of Remp's Ceiling Paintings in Palais Attems in Graz. From Reproductive Prints to Frescoes). V drugem delu je Edgar Lein predstavil ceno in vrednost slikarskih del okrog 1700 (Preis und Wert der Malerei um 1700), Tina Košak pa je na podlagi virov v mestnem arhivu v Antwerpnu raziskala trgovce $\mathrm{z}$ umetninami iz družine Forchondt in njihove štajerske stranke (The Forchondt Art Dealers and their Styrian Clients. Excerpts from the Antwerp City Archives). Renata Komić Marn je analizirala portrete Eleonore Marije Rozalije kneginje Eggenberg (The Portraits of Eleonora Maria Rosalia Princess of Eggenberg), Polona Vidmar pa je predstavila slikane genealogije štajerskega plemstva okrog leta 1700 (Gemalte Genealogien des steirischen Adels um 1700). Meje historične Štajerske so s svojimi referati presegli Ulrich Becker, ki je Stephanu Kesslerju pripisal upodobitvi Rešitve 
Dunaja leta 1683 (Weltgeschichte als Wimmelbild. Stephan Kessler und der Entsatz von Wien 1683), Andreas Gamerith, ki se je ukvarjal s stropnimi poslikavami pred Trogerjem oziroma okrog leta $1700 \mathrm{v}$ samostanih Zwettl in Altenburg (Vor Troger. Aspekte der Wandmalerei um 1700 am Beispiel der Klöster Zwettl und Altenburg), ter Martin Mádl z izčrpnim predavanjem o češkem stropnem slikarstvu okoli 1700 („So ist nun ... der Pracht im Bauen so hoch gestiegen ..... Profane Ceiling Painting in Bohemia around 1700).

Udeleženci simpozija so svoje referate pripravili za tisk ali pa so prispevali nova raziskovalna spoznanja, ki jih v Acta historiae artis Slovenica objavljamo pod naslovom Frančišek Karel Remb in slikarstvo v habsburških dednih deželah okrog leta 1700. Prispevka Karin Požin in Georga Lechnerja poglabljata vedenje o Rembovih stenskih poslikavah v palači Attems in o delih, ki jih je ustvaril po selitvi na Dunaj. Nekatere Rembove oljne slike so obravnavane tudi v prispevkih Edgarja Leina, ki se je posvetil stroškom za slike na Štajerskem, ter Renate Komić Marn, ki je raziskala slike iz Attemsove zbirke v Slovenski Bistrici v slovenskih javnih zbirkah. Slikarstvo zadnjih desetletij 17. stoletja je tema prispevkov Polone Vidmar, ki se je posvetila delom Dominika Frančiška Kalina von Marienberga za Habsburžane, in Ulricha Beckerja, ki je upodobitvi Rešitve Dunaja atribuiral tirolskemu slikarju Stephanu Kesslerju. Andreas Gamerith je Gallerio maior v samostanu Zwettl predstavil kot eksperiment v stropnem slikarstvu poznega 17. stoletja v Spodnji Avstriji, zvezek pa zaključuje prispevek Martina Mádla, ki se je posvetil transformaciji srednjeevropskega slikarstva okrog leta 1700 in pomembnim zgledom zanjo.

Upava, da bodo raznoliki prispevki in številne upodobitve spodbudili nadaljnje raziskovanje baročnega slikarstva. 


\section{Preface}

\section{Franz Carl Remp and Painting in THE HABSbURg Hereditary LANDS AROUND 1700}

The oeuvre of Radovljica born painter Franz Carl Remp (1675-1718) who worked in Graz and Vienna is little-known to the wider public despite his relatively numerous paintings. The first and only exhibition of Remp's works up to now was held from 26 October 1973 to 19 May 1974 at the Lower Belvedere in Vienna, and in the corner room of the present-day Universalmuseum Joanneum's Alte Galerie in Neutorgasse in Graz in June 1974. The exhibition catalogue entitled Der Barockmaler Franz Carl Remp 1674-1718 includes a seven-page introduction to the artist's life and work, a catalogue comprising twenty units, a chronology, and list of sources.

Georg Lechner researched Franz Carl Remp in his PhD thesis, which he defended 2010 in Vienna. In the spring of 2018, Lechner drew attention to the fact that the $300^{\text {th }}$ anniversary of the painter's death would occur in the autumn of the same year, and that neither Vienna nor Graz planned to commemorate the anniversary with an exhibition of the Baroque painter's works. We therefore decided to organize a conference entitled Painters and Patrons. Franz Carl Remp and Painting in Styria around 1700 that was held on 23 November 2018 at the Laterneng'wölb in the Eggenberg Castle. The following day the participants went on a tour of the Palais Attems, guided by Georg Lechner, as well as a tour of Eggenberg Castle's monumental rooms guided by Paul Schuster. The conference was supported by the Universities of Graz and Maribor, and the Research Centre of the Slovenian Academy of Sciences and Arts, the France Stele Institute of Art History. It formed part of the bilateral project BI SLO-AT/16-17-18: Art Patrons as Carriers of Province's Identity. The Role and Significance of Commissioners of Architectures and Furnishings of Aristocratic Residences and Pilgrimage Sites in Styria, which was financed by the Slovenian Research Agency and the Österreichischer Austauschdienst, and the research project J6-7410: Visual Representations of the Nobility. Early Modern Art Patronage in the Styria Province (2016-2018), financed by the Slovenian Research Agency.

The conference opened with Georg Lechner's general and foundational contribution - Franz Carl Remp between Graz and Vienna (Franz Carl Remp zwischen Graz und Wien) - followed by Christine Rabensteiner, who presented the works of immigrant and Styria-born Baroque painters in storage in the Alte Galerie in Graz (Werke immigrierter und gebürtiger steirischer Barockmaler. Ein Blick in das Depot der Alten Galerie), and Karin Požin with her study of Remp's ceiling paintings in Palais Attems in Graz and their sources (Case Study of Remp's Ceiling Paintings in Palais Attems in Graz. From Reproductive Prints to Frescoes). In the second part of the conference there were papers on the wider context and Styrian art of the period. Edgar Lein gave a spech on the cost and value of paintings around 1700 (Preis und Wert der Malerei um 1700). Tina Košak presented a study of the art dealers from the Forchondt family and their Styrian clients based on sources in the Antwerp city archives (The Forchondt Art Dealers and their Styrian Clients. Excerpts from the Antwerp City Archives). Renata Komić Marn analysed the portraits of Eleonora Maria Rosalia Princess of Eggenberg (The Portraits of Eleonora Maria Rosalia Princess of Eggenberg), and Polona Vidmar presented the painted genealogies of Styrian nobility around 1700 (Gemalte Genealogien des steirischen Adels um 
1700). The final section of the conference went beyond the borders of historical Styria: Ulrich Becker attributed the depictions of the Liberation of Vienna in 1683 to Stephan Kessler (Weltgeschichte als Wimmelbild. Stephan Kessler und der Entsatz von Wien 1683); Andreas Gamerith dealt with ceiling paintings in the Zwettl and Altenburg monasteries before Troger (Vor Troger. Aspekte der Wandmalerei um 1700 am Beispiel der Klöster Zwettl und Altenburg), and Martin Mádl gave a detailed paper on Czech ceiling painting around 1700 („So ist nun ... der Pracht im Bauen so hoch gestiegen .... Profane Ceiling Painting in Bohemia around 1700).

The conference participants prepared their papers for publication, or contributed new research findings, which are now being published in the Acta historiae artis Slovenica under the title Franz Carl Remp and Painting in the Habsburg Hereditary Lands around 1700. The contributions by Karin Požin and Georg Lechner deepen our knowledge of Remp's ceiling paintings in the Palais Attems, as well of the works he created after moving to Vienna. Some of Remp's oil paintings are also treated in the papers by Edgar Lein, who focuses on the cost of paintings in Styria, and by Renata Komić Marn, who discusses the paintings from the Attems collection in Slovenska Bistrica in Slovenian public collections. The topic of the papers by Polona Vidmar, who focuses on Dominik Franz Kalin von Marienberg's works for the Habsburg family, and Ulrich Becker, who attributes the depictions of the Liberation of Vienna to Tyrolian painter Stephan Kessler, is the painting of the last decades of the $17^{\text {th }}$ century. Andreas Gamerith discusses the Galleria maior in the Zwettl monastery as an experiment in ceiling painting in late $17^{\text {th }}$ century Lower Austria. The volume is concluded by Martin Mádl's contribution, which focuses on the transformation of Central European painting around 1700 and the models that were important for this transformation.

We hope that the diverse contributions and the numerous depictions will encourage further research in Baroque painting. 


\section{VORWORT}

\section{Franz CARl Remp UNd die MAlerei IN DEN HABSBURGISCHEN ERBLANDEN \\ UM 1700}

Trotz einer relativ großen Anzahl von Gemälden ist das CEuvre des in Radovljica in Slowenien geborenen und in Graz sowie Wien tätigen Malers Franz Carl Remp (1675-1718) einer breiten Öffentlichkeit bislang weitgehend unbekannt geblieben. Die erste und bislang einzige Ausstellung mit Werken des Malers wurde vom 26. Oktober 1973 bis zum 19. Mai 1974 im Unteren Belvedere in Wien und im Juni 1974 im Ecksaal der Alten Galerie des Joanneums in der Grazer Neutorgasse gezeigt. Das Katalogbändchen mit dem Titel Der Barockmaler Franz Carl Remp 1674-1718 enthält eine sieben Seiten umfassende Einführung zu Leben und Werk des Künstlers, einen Katalogteil mit zwanzig Einträgen, eine Zeittafel und ein Literaturverzeichnis.

Georg Lechner hat sich im Rahmen seiner 2010 in Wien abgeschlossenen Dissertation umfassend mit Franz Carl Remp befasst. Als Lechner im Frühjahr 2018 darauf hinwies, dass sich der 300. Todestag des Malers im Herbst nähere, aber weder in Wien noch in Graz eine Ausstellung mit Werken des Barockmalers geplant sei, beschlossen die Herausgeber, eine Tagung zu organisieren, die am 23. November 2018 unter dem Titel Maler und Auftraggeber. Franz Carl Remp und die Malerei in der Steiermark um 1700 im Laterneng'wölb von Schloss Eggenberg abgehalten wurde. Ergänzend dazu gab es am darauffolgenden Tag eine Besichtigung des Palais Attems unter der Leitung von Georg Lechner sowie eine Führung von Paul Schuster durch die Prunkräume von Schloss Eggenberg. Die von den Universitäten in Graz und Maribor sowie dem France Stele Institut für Kunstgeschichte am Forschungszentrum der Slowenischen Akademie der Wissenschaften und Künste unterstützte Veranstaltung war Teil des von der Slowenischen Forschungsagentur und dem Österreichischen Austauschdienst finanzierten bilateralen Projekts BI SLO-AT/16-17-18: Art Patrons as Carriers of Province's Identity. The Role and Significance of Commissioners of Architectures and Furnishings of Aristocratic Residences and Pilgrimage Sites in Styria sowie des von der Slowenischen Forschungsagentur finanzierten Forschungsprojekts J6-7410: Visual Representations of the Nobility. Early Modern Art Patronage in the Styria Province (2016-2018).

Den Anfang der Tagung machten Georg Lechner mit einem grundlegenden Vortrag über Franz Carl Remp zwischen Graz und Wien und Christine Rabensteiner mit Werke immigrierter und gebürtiger steirischer Barockmaler. Ein Blick in das Depot der Alten Galerie sowie Karin Požin mit einer Case Study of Remp's Ceiling Paintings in Palais Attems in Graz. From Reproductive Prints to Frescoes. Im zweiten Teil untersuchten Edgar Lein Preis und Wert der Malerei um 1700 und Tina Košak The Forchondt Art Dealers and their Styrian Clients. Excerpts from the Antwerp City Archives. Renata Komić Marn analysierte The Portraits of Eleonora Maria Rosalia Princess of Eggenberg und Polona Vidmar präsentierte Gemalte Genealogien des steirischen Adels um 1700. Den Blick über die Steiermark hinaus weiteten Ulrich Becker mit seinem Vortrag Weltgeschichte als Wimmelbild. Stephan Kessler und der Entsatz von Wien 1683, Andreas Gamerith mit einem Blick auf die Malerei Vor Troger. Aspekte der Wandmalerei um 1700 am Beispiel der Klöster Zwettl und Altenburg und Martin Mádl mit einem umfassenden Vortrag zum Thema „So ist nun ... der Pracht im Bauen so hoch gestiegen ..... Profane Ceiling Painting in Bohemia around 1700. 
Die Referenten und Referentinnen überarbeiteten ihre Vorträge für die Drucklegung oder präsentierten neue Forschungsergebnisse, die wir in den Acta historiae artis Slovenica unter dem Titel Franz Carl Remp und die Malerei in den habsburgischen Erblanden um 1700 veröffentlichen. Die Beiträge von Karin Požin und Georg Lechner erweitern das Wissen über Remps Wandmalereien im Palais Attems und über sein nach der Übersiedlung nach Wien geschaffenes Werk. Einige Ölgemälde Remps werden auch in den Beiträgen von Edgar Lein, der sich den Kosten für Gemälde in der Steiermark widmet, und Renata Komić Marn, die die Gemälde der ursprünglich in Schloss Slovenska Bistrica befindlichen Sammlung Attems in slowenischen öffentlichen Sammlungen untersucht, behandelt. Die Malerei in den letzten Jahrzehnten des 17. Jahrhunderts ist das Thema der Beiträge von Polona Vidmar, die die Werke Dominik Franz Calins von Marienberg für das Haus Habsburg präsentiert, und Ulrich Becker, der zwei Darstellungen des Entsatzes von Wien dem Tiroler Maler Stephan Kessler zuschreibt. Andreas Gamerith thematisiert die Galleria maior in Stift Zwettl als ein Experiment der Deckenmalerei des späten 17. Jahrhunderts in Niederösterreich. Der Band endet mit dem Beitrag von Martin Mádl, der sich der Transformation der mitteleuropäischen Wandmalerei um 1700 und ihren bedeutenden Vorbildern widmet.

Wir hoffen, dass die vielfältigen Beiträge und die zahlreichen Abbildungen zu einer weiteren Beschäftigung mit der Barockmalerei anregen werden.

Edgar Lein, Polona Vidmar 


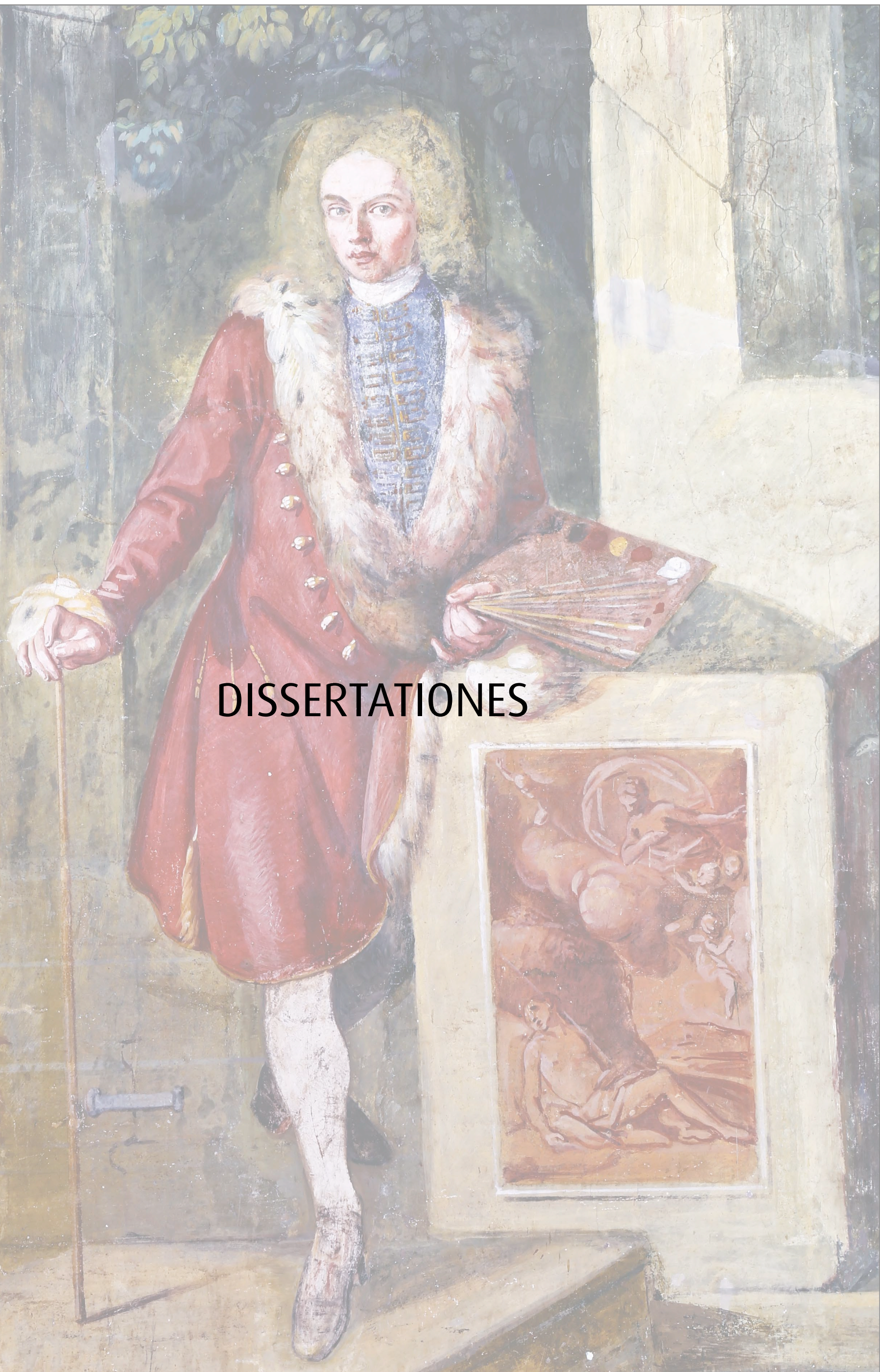




\title{
Preis und Wert der Malerei um 1700 $\mathrm{Zu}$ den Kosten von Gemälden in der Steiermark
}

\author{
Edgar Lein \\ Dr. Edgar Lein, Körblergasse 59, A-8010 Graz, \\ edgar.lein@gmx.at
}

Izvleček:

Cena in vrednost slik okrog leta 1700 . O stroških za slike na Štajerskem

1.01 Izvirni znanstveni članek

Pričujoči prispevek nudi pregled stroškov za oljne slike in zlasti oltarne podobe v času od konca osemdesetih let 17. stoletja do okrog leta 1750 na Štajerskem. Na podlagi dokumentiranih izplačil Frančišku Karlu Rembu, Hansu Adamu Weissenkircherju, Johannu Veitu Hauckhu, Franzu Ignazu Flurerju, Lucasu de Schramu in Johannu Baptistu Scheitu je pripravljen pregled vsot, ki so jih umetnikom izplačali za njihova dela. Dražje so bile oltarne slike beneških umetnikov, na primer na Dunaju delujočega Antonia Belluccija ali nemškega slikarja Johanna Carla Lotha, ki je deloval v Benetkah. Ugotovimo lahko, da cene oljnih slik okrog leta 1700 niso bile odvisne samo od velikosti slik in števila upodobljenih figur, ampak tudi od ugleda umetnikov in finančnih zmožnosti naročnikov. Domnevati smemo, da so bile slike za graške cerkve in samostane v splošnem dražje od slik, namenjenih okoliškim krajem ali območjem ob meji habsburškega cesarstva.

Ključne besede: cene slik, oljno slikarstvo, oltarne slike, Frančišek Karel Remb, Hans Adam Weissenkircher, Johann Veit Hauckh, Franz Ignaz Flurer, Lucas de Schram, Johann Baptist Scheit, Antonio Bellucci, Johann Carl Loth, cesar Karel VI.

Abstract:

The Price and Value of Paintings Around 1700. The Cost of Paintings in Styria

1.01 Original scientific article

The present paper offers an overview of the costs of oil paintings and especially of altar paintings in Styria from the 1680 s to circa 1750 . The compilation of the sums that the artists received for their works is prepared based on the documented payments to Franz Carl Remp, Hans Adam Weissenkircher, Johann Veit Hauckh, Franz Ignaz Flurer, Lucas de Schram, and Johann Baptist Scheit. The altar paintings of Venetian artists, for example, Antonio Bellucci, who worked in Vienna, or the German painter Johann Carl Loth, who worked in Venice, were more expensive. It can also be established that around 1700, the prices of oil paintings were dependent not only on the size of the paintings and the number of the figures depicted, but also on the reputation of the artists and the financial means of the patrons. It can be presumed that paintings produced for the churches and monasteries in Graz were generally more expensive than the paintings intended for the surrounding towns or the areas on the borders of the Habsburg Empire.

Keywords: prices of paintings, oil painting, altar paintings, Franz Carl Remp, Hans Adam Weissenkircher, Johann Veit Hauckh, Franz Ignaz Flurer, Lucas de Schram, Johann Baptist Scheit, Antonio Bellucci, Johann Carl Loth, Emperor Charles VI 
Der vorliegende Beitrag bietet eine Zusammenstellung der Kosten, die für Gemälde und insbesondere Altarbilder von Franz Carl Remp und anderen Malern vom Ende der 1680er Jahre bis 1750 hauptsächlich in der Steiermark aufgewendet werden mussten. ${ }^{1}$ Derartige Untersuchungen gibt es bisher nur für andere Kunstlandschaften, insbesondere für Italien. Grundlegend zu den Preisen, die in Italien für Gemälde gezahlt wurden, sind die Publikationen The Art Market in Italy. $15^{\text {th }}-17^{\text {th }}$ Centuries und Painting for Profit. The Economic Lives of Seventeenth-Century Italian Painters. ${ }^{2}$ Ergänzend dazu haben Nina Kudiš und Marin Bolić 2019 den Wert und die Preise einiger Gemälde in Venedig, Istrien und Dalmatien zusammengestellt. ${ }^{3}$ Die Entwicklung der Preise von Kunstwerken in Mitteleuropa ist Gegenstand des Tagungsbandes Kunstmärkte zwischen Stadt und Hof. Prozesse der Preisbildung in der europäischen Vormoderne. ${ }^{4}$ Im Unterschied zu den genannten Veröffentlichungen, in denen vor allem die Preise auf dem Kunstmarkt untersucht wurden, werden in diesem Beitrag nur die Summen genannt und miteinander verglichen, die den Malern von den Auftraggebern unmittelbar ausbezahlt wurden.

Die Frage nach den Kosten für die Gemälde von Franz Carl Remp kann anhand einiger vom Künstler im Auftrag des Benediktinerstifts Kremsmünster in Oberösterreich geschaffener Werke beantwortet werden. Über den Seitenaltären der Stiftskirche zu Kremsmünster befinden sich zwei großformatige Gemälde, auf denen Christus am Kreuz und Der Tod des hl. Benedikt dargestellt sind (Abb. 1-2). ${ }^{5}$ Die beiden Altarbilder wurden im Frühjahr 1712 fertiggestellt und bezahlt. Bereits am 10. Januar 1712 hatte Remp vom Abt des Stiftes Kremsmünster 300 Gulden erhalten. ${ }^{6}$ Am 27. Mai desselben Jahres wurde ihm dann eine abschließende Zahlung in Höhe von weiteren 300 Gulden für die beiden Altarbilder übergeben. ${ }^{7}$ Wenn beide Gemälde mit diesen zwei Zahlungen in Höhe

1 Der Beitrag basiert auf dem Vortrag „Preis und Wert der Malerei um 1700“, der 2018 anlässlich der Tagung „Franz Carl Remp und die Malerei in der Steiermark um 1700“ in Graz gehalten wurde. Nicht berücksichtigt wurden die Kosten für wandfeste Gemälde, insbesondere Deckenfresken. Es war nicht in allen Fällen möglich, die in der Literatur meist nur auszugsweise zitierten Dokumente in den Archiven auf den richtigen Wortlaut zu überprüfen und zu ergänzen. Auch war es nicht möglich, sämtliche Maße der Altarbilder zu ermitteln. Für Hinweise und Unterstützung bei der Ausarbeitung des Textes und der Beschaffung der Abbildungen danke ich Dr. Norbert Allmer, Lara Baumgartner BA, Prof. Dr. Günther Bernhard, Dr. Erik Hilzensauer, Pater Mag. Josef Höller, Bettina Hutzl MA, Dr. Barbara Kaiser, Propst Mag. Bernhard Mayrhofer, Mag. Karl Peitler, Dr. Christine Rabensteiner, Provinzialminister Pater Oliver Ruggenthaler, Dompropst Dr. Heinrich Schnuderl, Dr. Elisabeth Schöggl-Ernst, Prof. Dr. Polona Vidmar, Dr. Norbert Weiss und Priv.-Doz. Dr. Dr. Peter Wiesflecker. Für die großzügige Überlassung von Fotos danke ich MMag. Markus Enzinger, Mag. art. Eva Kleinsasser, Prof. Dr. Matej Klemenčič, Dr. Georg Lechner und Gabriele Roithner vom Bundesdenkmalamt in Wien.

2 The Art Market in Italy. $15^{\text {th }}-17^{\text {th }}$ centuries/Il mercato dellarte in Italia. Secc. XV-XVII (Hrsg. Marcello Fantoni, Louisa C. Matthew, Sara F. Matthews-Grieco), Modena 2003; Painting for Profit. The Economic Lives of Seventeenth-Century Italian Painters (Hrsg. Richard E. Spear, Philip L. Sohm), New Haven-London 2010.

3 Nina KUDIŠ, Marin BOLIĆ, Value and Prices of Paintings in Venice, Istria and Dalmatia during the $17^{\text {th }}$ Century (Some Examples), Imaging the Image/Lik slike (Hrsg. Nataša Lah, Nenad Miščević, Miško Šuvaković), Rijeka 2019, S. 83-92.

4 Kunstmärkte zwischen Stadt und Hof. Prozesse der Preisbildung in der europäischen Vormoderne (Hrsg. Andreas Tacke), Petersberg 2017.

5 Georg Matthias LECHNER, Der Barockmaler Franz Carl Remp (1675-1718), Wien 2010 (ungedruckte Dissertation), S. 165-166, G 83 und G 84. Die Maße der Altargemälde an den Seitenaltären der Stiftskirche Kremsmünster werden in Die Kunstdenkmäler des Benediktinerstiftes Kremsmünster. 1: Das Stift - Der Bau und seine Einrichtung (Bearb. Erika Doberer), Wien 1977 (Österreichische Kunsttopographie, 43), S. 262 mit 360 x $234 \mathrm{~cm}$ angegeben.

6 Siehe dazu Archivalische Vorarbeiten zur Österreichischen Kunsttopographie. Gerichtsbezirk und Stift Kremsmünster (Hrsg. Willibrord Neumüller), 2, Wien 1961, S. 69, Nr. 2969.

7 Stiftsarchiv Kremsmünster, Kammereirechnungen, 1712, Nr. 507, zitiert nach Archivalische Vorarbeiten zur Österreichischen Kunsttopographie. Gerichtsbezirk und Stift Kremsmünster (Hrsg. Willibrord Neumüller), 1, Wien 1961, 


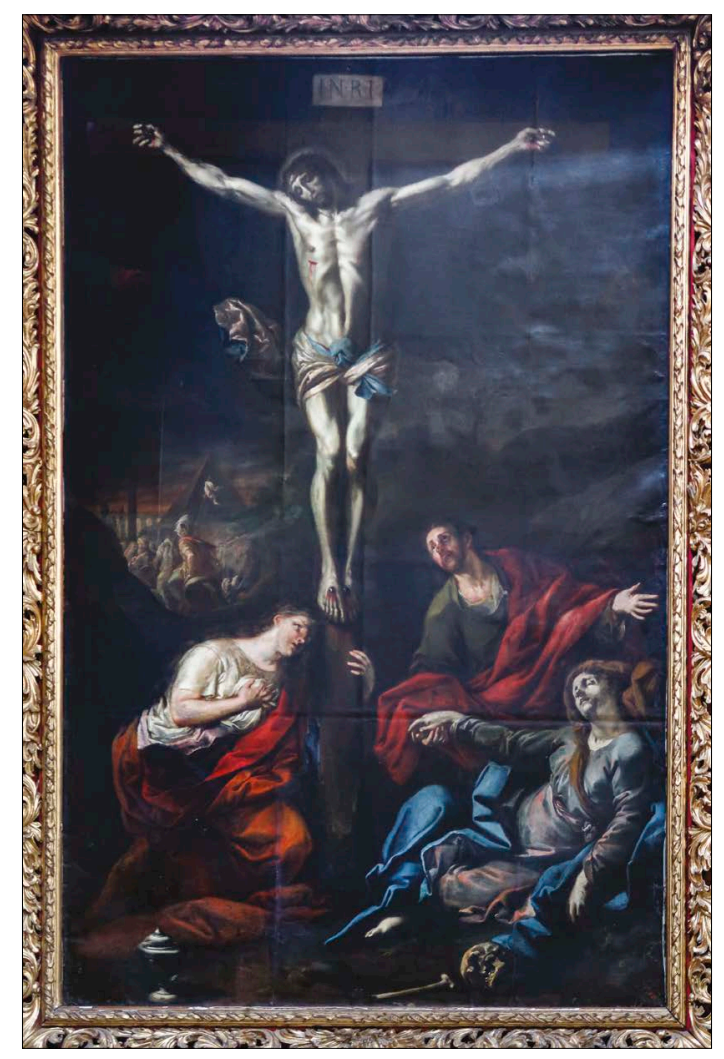

1. Franz Carl Remp: Christus am Kreuz, 1712, Stiftskirche, Benediktinerstift Kremsmünster

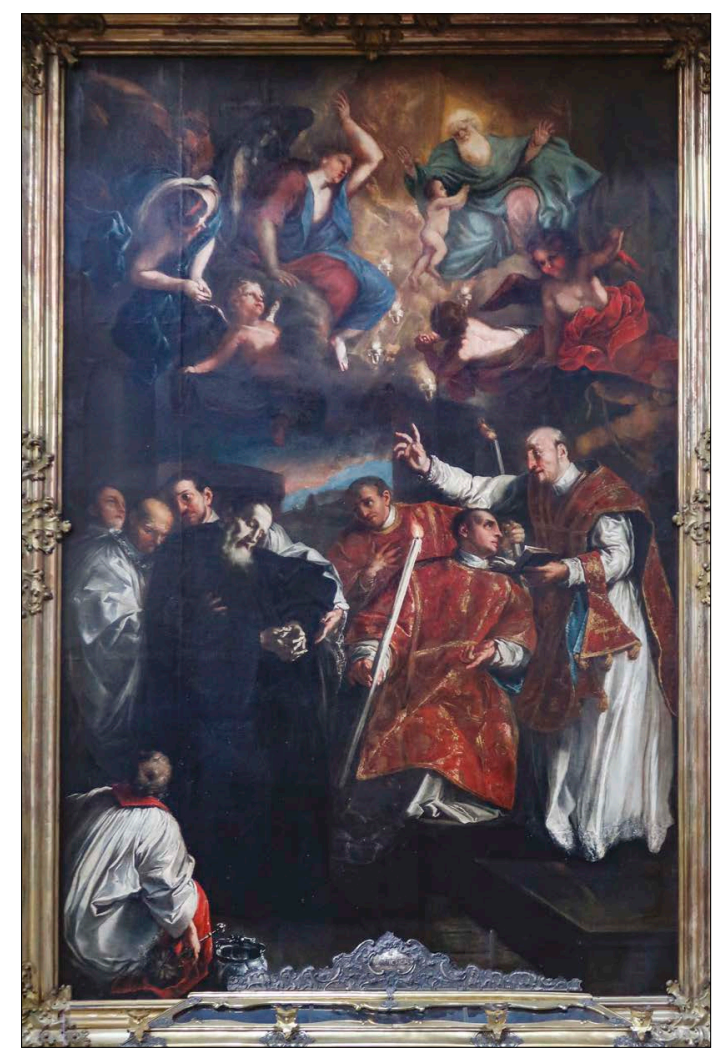

2. Franz Carl Remp: Der Tod des hl. Benedikt, 1712, Stiftskirche, Benediktinerstift Kremsmünster

von je 300 Gulden vollständig abgegolten waren, dann kostete Anfang des 18. Jahrhunderts ein großformatiges Altarbild von Franz Carl Remp 300 Gulden.

Im darauffolgenden Jahr wurden insgesamt 13 Gemälde des Künstlers mit Darstellungen der Gründungsgeschichte des Stiftes sowie der für den Benediktinerorden und die Verbreitung des Glaubens bedeutenden Heiligen, ${ }^{8}$ die an den Pfeilern der Stiftskirche Kremsmünster angebracht wurden, mit je 200 Gulden, also insgesamt 2600 Gulden bezahlt. ${ }^{9}$ Wegen des etwas kleineren Formats der Gemälde erscheint der gegenüber den beiden von Remp zuvor geschaffenen Altarbildern um 100 Gulden geringere Preis durchaus angemessen. Die Gemälde wurden im 19. Jahrhundert aus der Stiftskirche entfernt. Die Auffindung des toten Gunther und Das Begräbnis Gunthers

S. 278, Nr. 2969: Den 27. May Franz Carl Rempen für die in die Closter Kürchen gemahlene 2 Altar blöther alß S. Benedictum moribundum, vnd das andere Christus am Crë̈z, einen Rest zalt $300 \mathrm{fl}$. Vollständige Abschrift bei Ida SCHMITZ, Kirche und Kloster der Ursulinen in Graz. Ein Beitrag zur steiermärkischen Kunstgeschichte, Graz 1927 (ungedruckte Dissertation), S. 87, Nr. 507, und LECHNER 2010 (Anm. 5), S. 211.

8 Siehe dazu LECHNER 2010 (Anm. 5), S. 59-62.

9 Stiftsarchiv Kremsmünster, Kammereirechnungen, 1713, Nr. 443, zitiert nach Archivalische Vorarbeiten 1961 (Anm. 7), S. 280, Nr. 2989: Dem Carl Rempen wegen deren alhiesiger Closter Kürchen an denen Pfeilern aufgemachten 13 bilder, aines $200 \mathrm{fl}$ zusammen $2600 \mathrm{fl}$. Vollständige Abschrift bei SCHMITZ 1927 (Anm. 7), S. 87, Nr. 443, und LECHNER 2010 (Anm. 5), S. 212. Die Kunstdenkmäler des Benediktinerstiftes Kremsmünster 1977 (Anm. 5), S. 278, gibt die Maße mit je $320 \times 164 \mathrm{~cm}$ an. 


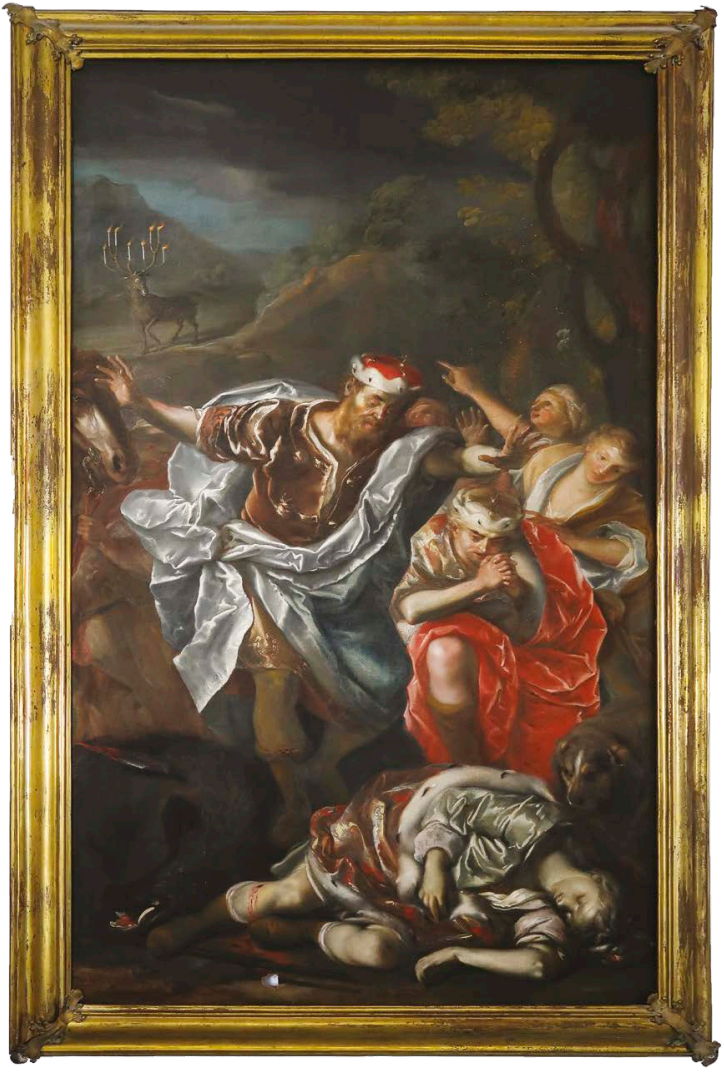

3. Franz Carl Remp: Die Auffindung des toten Gunther, 1713, Benediktinerstift Kremsmünster

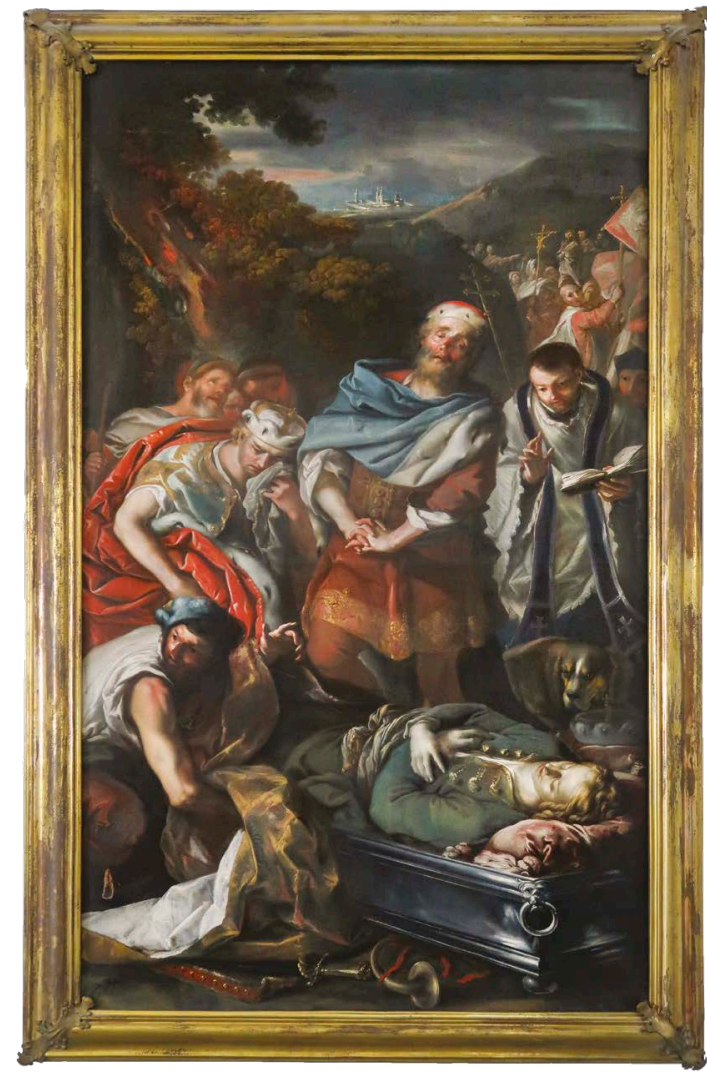

4. Franz Carl Remp, Das Begräbnis Gunthers, 1713, Benediktinerstift Kremsmünster

(Abb. 3-4) befinden sich heute im Stift, ${ }^{10}$ sechs weitere Gemälde in der Pfarrkirche von Pfarrkirchen bei Bad Hall, ${ }^{11}$ die anderen fünf Gemälde wurden 1866 bei einem Brand im Meierhof des Stiftes Kremsmünster zerstört. ${ }^{12}$

Außerdem erhielt Remp am 26. Mai 1713 eine Zahlung in Höhe von 100 Gulden für drei Porträts Kaiser Karls VI. ${ }^{13}$ Ein ganzfiguriges und lebensgroßes Bildnis des Kaisers in Rüstung und rotem, hermelinverbrämtem Umhang mit Zepter, Kaiserkrone und Erzherzogshut befindet sich heute im Bilderdepot des Stiftes Kremsmünster. ${ }^{14}$ Aufgrund der relativ geringen Gesamtsumme für drei Bildnisse des Kaisers ist anzunehmen, dass die beiden anderen, heute verschollenen Gemälde im Format wesentlich kleiner waren und den Porträtierten in einem engeren Bildausschnitt zeigten. ${ }^{15}$ Aus dem Vergleich mit drei im Format sehr ähnlichen Supraporten, die der Maler für

10 LECHNER 2010 (Anm. 5), S. 168-169, G 87 und G 88.

11 LECHNER 2010 (Anm. 5), S. 174-177, G 96-G 101. Siehe dazu Karl HOCHHUBER, Pfarrkirchen bei Bad Hall, Oberösterreich, Salzburg 1962 (Christliche Kunststätten Österreichs, 24), S. $24-27$.

12 Die Kunstdenkmäler des Benediktinerstiftes Kremsmünster 1977 (Anm. 5), S. 268-269.

13 Stiftsarchiv Kremsmünster, Kammereirechnungen, 1713, Nr. 411, zitiert nach Archivalische Vorarbeiten 1961 (Anm. 7), S. 280, Nr. 2987: Den 26. May Franz Carl Rempen für 3 Contrafait deß iezigen Kaysers Caroli VI. zalt 100 fl. Vollständige Abschrift bei SCHMITZ 1927 (Anm. 7), S. 87, Nr. 441, und LECHNER 2010 (Anm. 5), S. 212, Q 10.

14 LECHNER 2010 (Anm. 5), S. 169, G 89. Das Gemälde hat die Maße 214 x $141 \mathrm{~cm}$.

15 LECHNER 2010 (Anm. 5), S. 169, G 89 und Anm. 563. 

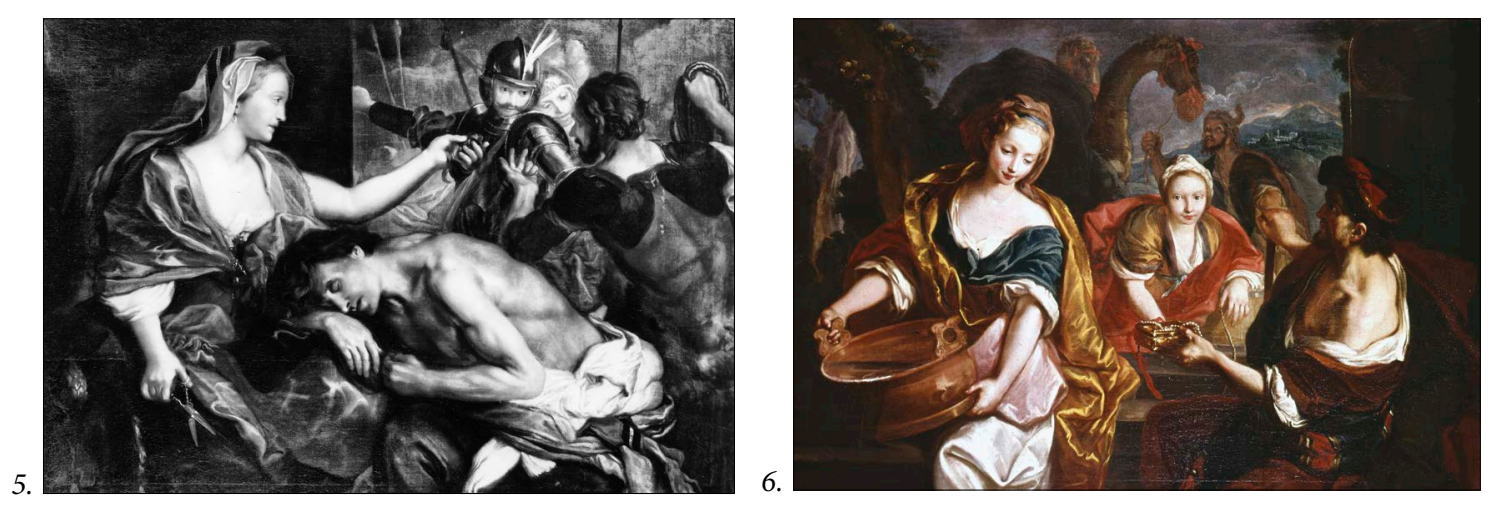

5. Franz Carl Remp: Samson und Dalila, 1715, Augustiner-Chorherrenstift St. Florian

6. Franz Carl Remp: Rebekka und Elieser am Brunnen, 1715, Augustiner-Chorherrenstift St. Florian

7. Franz Carl Remp: Hiob im Elend,

1715, Augustiner-Chorherrenstift St. Florian

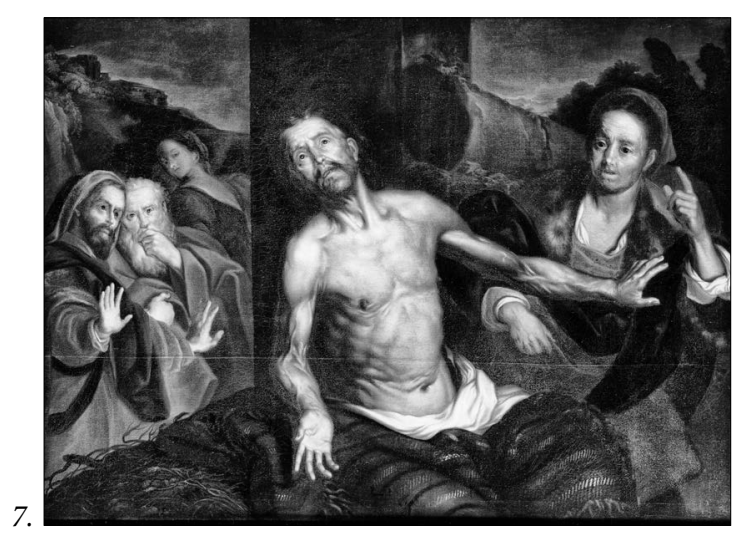

das Stift St. Florian schuf, kann geschlossen werden, dass das lebensgroße Porträt Karls VI. etwa 50 Gulden oder mehr gekostet hat, während für die beiden kleineren, halbfigurigen Bildnisse oder Bruststücke je 25 Gulden oder weniger gezahlt wurde.

Remps Gemälde für das Stift Kremsmünster wie auch seine Werke für das Stift St. Florian in Oberösterreich, die im Folgenden behandelt werden, wurden in den Jahren 1712, 1713 und 1715 geschaffen und gehören damit in die Schaffenszeit nach der Übersiedelung des Künstlers nach Wien, die vermutlich 1711 erfolgte. ${ }^{16}$

Für das Augustiner-Chorherrenstift St. Florian schuf Franz Carl Remp drei Historienbilder mit Darstellungen von Samson und Dalila, Rebekka und Elieser am Brunnen sowie Hiob im Elend (Abb. 5-7). ${ }^{17}$ Die Gemälde, die sich heute als Supraporten im Blauen Zimmer befinden, waren ursprünglich über den Türen des Grünen Zimmers, das in den Dokumenten auch Samson-Zimmer genannt wird, angebracht. Die Werke waren Anfang 1715 fertiggestellt, denn am 21. Februar dieses Jahres erhielt der in Wien lebende Maler für die drei Supraporten im Samson-Zimmer insgesamt 150 Gulden. ${ }^{18}$ Damit war der am 6. Juli 1714 zwischen Probst Franziskus von St. Florian und Franz

16 Remp wurde 1710 in Graz ein letztes Mal urkundlich erwähnt und lebte seit 1712 in Wien. Siehe dazu Der Barockmaler Franz Carl Remp 1674-1718, Österreichische Galerie, Wien und Joanneum Graz, Wien 1974, S. 12; LECHNER 2010 (Anm. 5), S. 13-14.

17 LECHNER 2010 (Anm. 5), S. 177-178, G 102-G 104. Die Gemälde haben die Maße 140 x $200 \mathrm{~cm}$.

18 Stiftsarchiv St. Florian, Baurechnung, 1715, zitiert nach LECHNER 2010 (Anm. 5), S. 215, Q 14c: Nr. 45: den 21. febr. Herrn franz Carl Remp Maler in Wien Vor drey Porthir stückh in das Sämson Zimmer alhier, vermög quittung, 150 [fl]. Vollständige Abschrift bei SCHMITZ 1927 (Anm. 7), S. 90. 
Carl Remp abgeschlossene Vertrag, in dem ihm für die Anfertigung dreier Supraporten je 50 Gulden zugesichert worden waren, erfüllt. ${ }^{19}$

$\mathrm{Zu}$ den von Remp in Graz oder der Steiermark geschaffenen Werken sind bislang keine Zahlungsbelege bekannt. Die für die Stifte Kremsmünster und St. Florian dokumentierten Zahlungen an den Künstler sind erste Richtwerte, die für die Kosten großformatiger Altarund Historienbilder ermittelt werden können. Es ist aber zu bedenken, dass die beiden oberösterreichischen Stifte zu den bedeutenden und reichen Klöstern gehören und Aufträge dieser Klöster möglicherweise besser vergütet wurden als Arbeiten für Stifte oder Kirchen in der Steiermark.

Um die Erkenntnisse über die Preise, die um 1700 für Gemälde in der Steiermark gezahlt wurden, zu erweitern, werden Remps Arbeiten im Folgenden mit vergleichbaren Werken anderer in Graz und der Steiermark tätiger Künstler in Beziehung gesetzt.

Der fürstlich Eggenbergische Hofmaler Hans Adam Weissenkircher (1646-1695) erhielt für das 1688 fertiggestellte Hochaltarbild

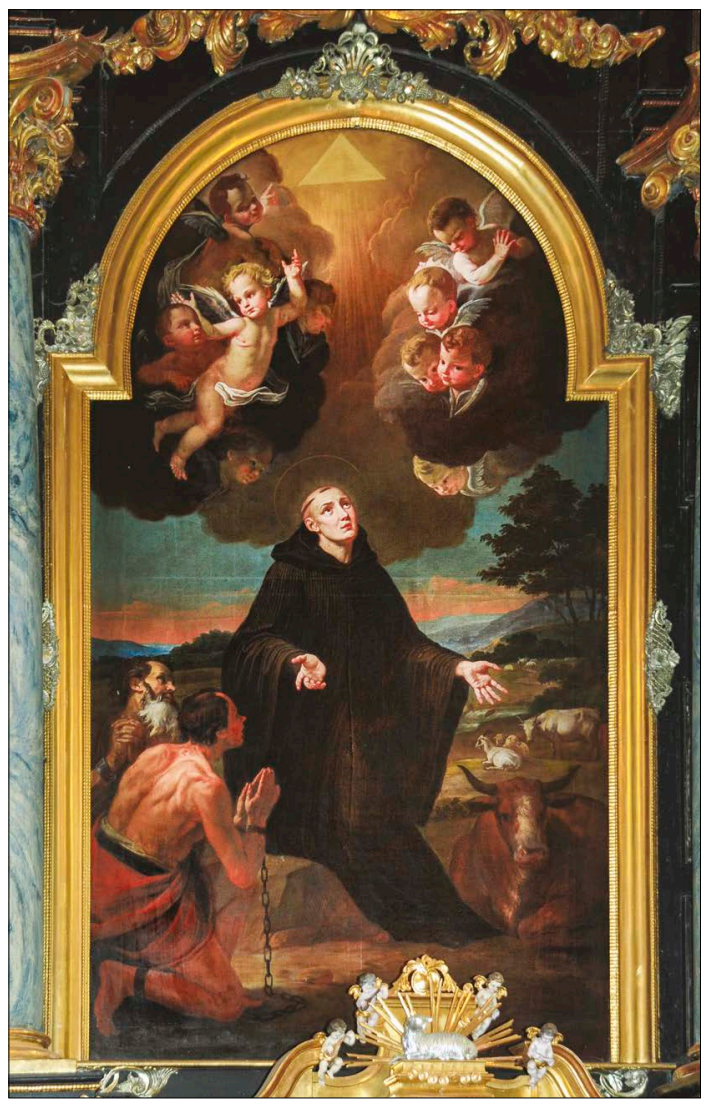

8. Hans Adam Weissenkircher: Der hl. Leonhard, 1688, ehem. Pfarrkirche St. Leonhard, Seewiesen mit dem hl. Leonhard in der Pfarrkirche des Heiligen in Seewiesen (Abb. 8) 200 Gulden. ${ }^{20}$ So jedenfalls wurde es am 11. November 1687 in dem Vertrag zwischen Abt Franziskus von St. Lambrecht und dem Maler vereinbart. ${ }^{21}$ Als Anzahlung hatte der Maler am selben Tag 50 Gulden erhalten

19 Stiftsarchiv St. Florian, Sonderkasten Kunstakten, 1714 Juli 6., zitiert nach Thomas KORTH, Stift St. Florian. Die Entstehungsgeschichte der barocken Klosteranlage, Nürnberg 1975 (Erlanger Beiträge zur Sprach- und Kunstwissenschaft, 49), S. 365, (429): Hierauf haben Wür mit herrn franz Carl Remp Kunst Malern Volgenten Contract gemacht, /.../ wie auch in das griene oder Samson Zī̄er in Neuen stockh Drey Porthir stuckh nach möglichister Kunst Und fleis Von seinen selbst aigenen schön = guet Und bestendigen farben Malen Und Verförttigen solle; Dargegen Versprechen Wür ihme H. Remp /.../Vor ain Porthir stuckh 50 fl. Vollständige Abschrift bei SCHMITZ 1927 (Anm. 7), S. 89, und LECHNER 2010 (Anm. 5), S. 214, Q 14a.

20 Anny ROSENBERG-GUTMANN, Hanns Adam Weissenkirchner. Sein Leben und seine Kunst, Wien-Graz-Leipzig 1925 (Beiträge zur Kunstgeschichte Steiermarks und Kärntens, 2), S. 41 und 63-64; Barbara RUCK, Hans Adam Weissenkircher, fürstlich Eggenbergischer Hofmaler (1646-1695). Mit einem Versuch zur Rekonstruktion des Programmes für seinen allegorischen Gemäldezyklus im Eggenberger Planetensaal, Graz 1982 (ungedruckte Dissertation), S. 383-384. Das vom Maler signierte und 1688 datierte Altarbild hat die Maße 310 x $170 \mathrm{~cm}$.

21 Stiftsarchiv St. Lambrecht, Spanzedl, 11. November 1687: Spanzedl zwischen Ihro Hochwürden undt gnaden H. Herrn Franciscum abbten zu St. Lambrecht eines, dan Herrn han $\beta$ adam weissenkircher malers andern theils. undt verspricht besagter Maler Ihr gnd. H. Prelathen ain altarblatt S. Leonardi, in die kirch undt Neuen altar auff die Seewisen sein fleis $\beta$ nach bestens $Z u$ mallen, wie Es ain entwurff beraits vorgezaigt hatt. wofür H Prelath Ihme Maller Zweihundert gulden Zu bezalln Versprecht. In Urkundt dessen sein 2 gleiche Spanzedl auffgericht undt beiderseits undterschriben worden. St. Gotthardt den 11. November 1687. Hievon zalt $50 \mathrm{fl}$. Auszugsweise zitiert bei 


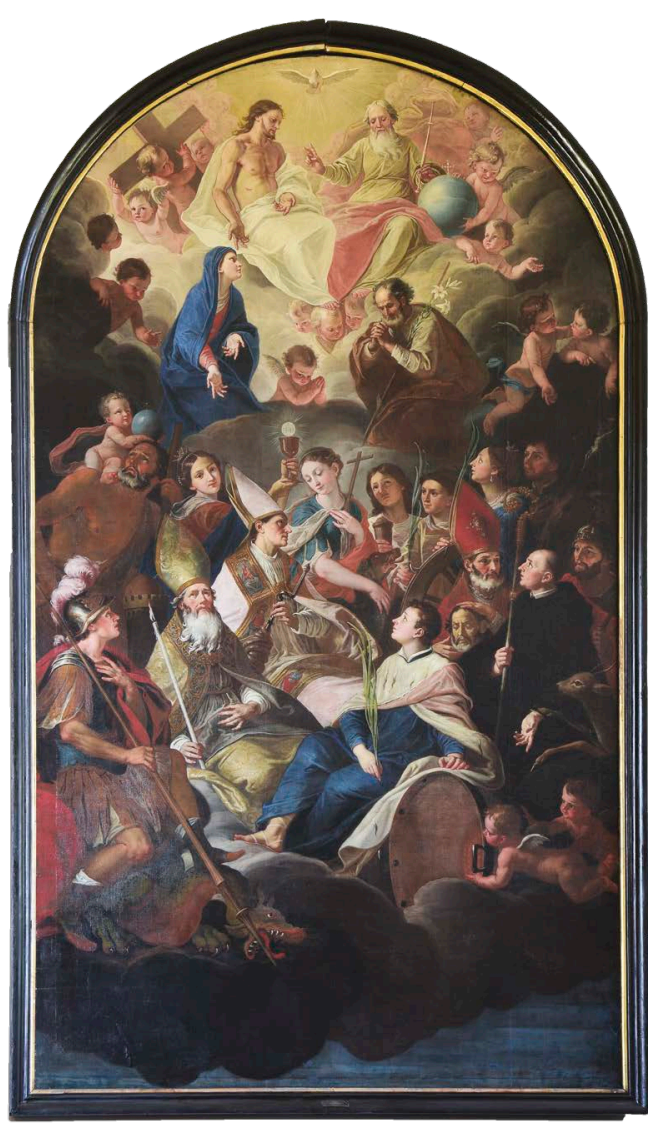

9. Hans Adam Weissenkircher: Die Heilige Dreifaltigkeit, Maria und Josef und die Vierzehn Nothelfer, 1692, Antoniuskirche, Graz und quittiert. ${ }^{22}$ Die für das Altarbild in Seewiesen überlieferten 200 Gulden sind die einzige dokumentierte Zahlung an den Maler Weissenkircher. Der Preis von 200 Gulden für ein großformatiges Altarbild von seiner Hand entspricht genau dem, was Franz Carl Remp 25 Jahre später für die im Format sehr ähnlichen Historienbilder an den Pfeilern der Stiftskirche Kremsmünster erhielt. In Relation dazu stehen auch die 400 Gulden, die Hans Adam Weissenkircher für das großformatige, 1692 geschaffene Altarbild mit der Heiligen Dreifaltigkeit, Maria und Josef sowie den Vierzehn Nothelfern (Abb. 9) erhalten haben soll. ${ }^{23}$ Das für die Grazer Kapuzinerkirche bestimmte Gemälde befindet sich heute in der Antoniuskirche. Laut Chronik des Kapuzinerordens war das Werk für einen Altar der Vierzehn Nothelfer bestimmt, der von Charlotte Polixena Gräfin Khisl gestiftet und 1692 in der letzten, heute vermauerten Kapelle errichtet wurde. Die außergewöhnliche Höhe der Kosten dieses Altarbilds ist wohl nicht nur durch die Größe des Werkes, sondern auch aufgrund der Vielzahl der dargestellten Personen - über den Vierzehn Nothelfern befinden sich Maria und Joseph, die Heilige Dreifaltigkeit sowie zahlreiche Engel - gerechtfertigt.

Wenn man die Summe von 400 Gulden als gesichert annimmt, dann wurde Hans Adam Weissenkircher für seine Arbeit fürstlich entlohnt, denn er stand seit dem 3. August 1678 als Hofmaler in Diensten des Fürsten Johann Seyfried von

Othmar WONISCH, Ein Beitrag zur Weissenkircher-Forschung, Zeitschrift des historischen Vereines für Steiermark, 11, 1913, S. 358. Vollständige, leicht veränderte Abschrift bei Anny ROSENBERG-GUTMANN, Hans Adam Weissenkircher, Graz 1924 (ungedruckte Dissertation), S. 102, Anhang I, I, und ROSENBERG-GUTMANN 1925 (Anm. 20), S. 63-64, V, 1. Siehe dazu RUCK 1982 (Anm. 20), S. 383-384, Kat. Nr. 80 und die Fotokopie des Dokuments im Anhang; Barbara RUCK, Hans Adam Weissenkircher (1646-1695). Fürstlich Eggenbergischer Hofmaler (Hrsg. Friedrich Kryza-Gersch), Graz 1985, S. 182, Nr. 83.

22 Stiftsarchiv St. Lambrecht, Quittung Weissenkirchers über 50 fl., 11. November 1687: Daß Ihro Hochwürden und Gnaden Herr Herr Franciscus Abbte zu St. Lamprecht pp. mir Endts Benanthen, auff die Arbeith des Seewisserischen Altar, in abschlag $50 \mathrm{fl}$ : par entricht und bezalt habe, bezeugt mein undtergesetzte Handschrifft und Pettschafftsförttigung. St. Gotthardt den 11. November 1687. Hanns Adam Weisßenkircher fürstl. Eggenbergischer Hoffmaler. Auszugsweise zitiert bei WONISCH 1913 (Anm. 21), S. 358. Vollständige, leicht veränderte Abschrift bei ROSENBERG-GUTMANN 1924 (Anm. 21), S. 102, Anhang I, II, und ROSENBERG-GUTMANN 1925 (Anm. 20), S. 64, V, 2. Siehe dazu RUCK 1982 (Anm. 20), S. 384, Kat. Nr. 80, und die Fotokopie des Dokuments im Anhang; RUCK 1985 (Anm. 21), S. 182, Nr. 84.

23 RUCK 1985 (Anm. 21), S. 166-167, Nr. 64. Siehe dazu Rochus KOHLBACH, Die barocken Kirchen von Graz, Graz 1951, S. 44-45, der die 400 Gulden nicht erwähnt. Das Altarbild misst 402 x $242 \mathrm{~cm}$. 
Eggenberg und erhielt in den ersten Jahren ein jährliches Gehalt in Höhe von 400 Gulden, ${ }^{24}$ das weit über dem seines Vorgängers Andreas Rämblmayr lag und sogar das Gehalt des höchsten Beamten im Eggenberger Hofstaat um 100 Gulden übertraf..$^{25}$ Allerdings wurden die Zahlungen von monatlich mehr als 33 Gulden im Jahr 1683 auf insgesamt 150 Gulden im Jahr begrenzt, weil die Kosten der Hofhaltung Johann Seyfrieds insgesamt zu hoch waren. ${ }^{26}$ Das immer noch sehr großzügige Jahresgehalt, das Weissenkircher fortan erhielt, wurde außerdem durch die Lieferung von verschiedenen Naturalien wie Wein, Weizen und anderem Getreide ergänzt. ${ }^{27}$

Als Hofmaler Johann Seyfrieds von Eggenberg schuf Weissenkircher zahlreiche Altarbilder zur Neuausstattung von Kirchen auf dem fürstlichen Territorium oder unter eggenbergischer Vogtei. ${ }^{28}$ Da diese Werke im Auftrag des Eggenbergers angefertigt wurden und die Arbeiten für den Fürsten mit dem Jahresgehalt abgegolten waren, liegen dazu keine Zahlungsbelege vor.

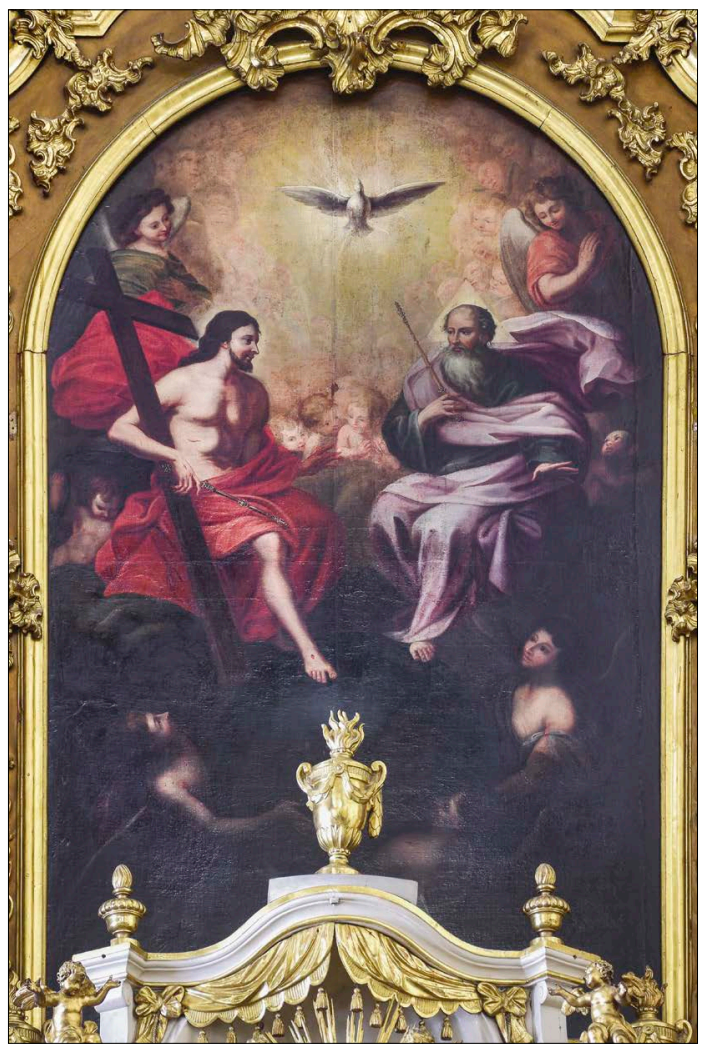

10. Johann Veit Hauckh: Die Heilige Dreifaltigkeit, 1702, Dreifaltigkeitskirche, Graz

Auch Weissenkirchers Schüler Johann

Veit Hauckh (1663-1746) war als Hofmaler in eggenbergischen Diensten tätig. ${ }^{29} 1699$ bewarb sich Hauckh jedoch um die Aufnahme in die Grazer Malerconfraternität. ${ }^{30}$ Grund für dieses Ansuchen

24 Steiermärkisches Landesarchiv (StLA), Archiv Herberstein, Eggenberger Rechnungsbücher, Faszikel 43 (1678/79), Fol. 25v, zitiert nach ROSENBERG-GUTMANN 1925 (Anm. 20), S. 64: /.../ dem maler Hannß Adamy Weissenkhürchner für seine arbeit monatlich 33 fl. 2 3. 20 d., absonderlich auch die farben und andere notwendigkeit zu bezalen. Als hab ich ihme seine monatsolt von 3. Augusti 1678 bis dahin 1679, von ainen ganzen jahr, laut quitung per $400 \mathrm{fl}$. /.../ bezalt /.../. Vollständig zitiert bei ROSENBERG-GUTMANN 1924 (Anm. 21), S. 103, Anhang II, und RUCK 1982 (Anm. 20), S. 24, Anm. 47.

25 RUCK 1982 (Anm. 20), S. 24; RUCK 1985 (Anm. 21), S. 21.

26 StLA, Archiv Herberstein, Eggenberger Rechnungsbücher, Faszikel 44 (1682/83), No. 232, zitiert nach ROSENBERG-GUTMANN 1925 (Anm. 20), S. 64, VI: Dem fürstl. Hoffmaller herrn Hannß Adam Weissenkhürcher, auf abschlag seiner jährlichen $150 \mathrm{fl}$ bestallung so sich den 1. Jenner 1683 verfallen, gegen Quittung bezalt /.../ 115.- fl. Vollständig zitiert bei ROSENBERG-GUTMANN 1924 (Anm. 21), S. 107.

$27 \mathrm{Zu}$ den an Hans Adam Weissenkircher geleisteten Abgaben in Naturalien, die in den Eggenberger Rechnungsbüchern verzeichnet sind, siehe ROSENBERG-GUTMANN 1924 (Anm. 21), S. 103-111, Anhang II; ROSENBERGGUTMANN 1925 (Anm. 20), S. 65-67, und RUCK 1985 (Anm. 21), S. 21.

28 RUCK 1982 (Anm. 20), S. 27; RUCK 1985 (Anm. 21), S. 23.

29 Anlässlich seiner Hochzeit am 21. Mai 1697 wird Johann Veit Hauckh im Trauungsbuch der Grazer Stadtpfarrkirche zum Hl. Blut, Band VII, S. 882, als „Fürstlich Eggenberg Hoffmaler“ bezeichnet. Siehe dazu Victoria REDL, Johann Veit Hauckh. Ein steirischer Barockmaler (1663-1746), Graz 1986 (ungedruckte Dissertation), S. 7-8 und S. 394-395, Anm. 10, mit dem vollständigen Eintrag im Trauungsbuch sowie RUCK 1985 (Anm. 21), S. 26, Anm. 35.

30 REDL 1986 (Anm. 29), S. 10. Zur Grazer Malerconfraternität siehe Josef WASTLER, Die Ordnung der von Peter 
des hofbefreiten Malers dürfte eine finanzielle Notlage Johann Seyfrieds von Eggenberg gewesen sein, die den Maler dazu zwang, sich auch außerhalb seines Dienstverhältnisses als Hofkünstler um Aufträge zu bemühen, was nur als Mitglied der Grazer Malerconfraternität möglich war.

Im Auftrag von Rosalia Maria Eleonora Reichsfürstin von Eggenberg schuf Johann Veit Hauckh 1702 das Altarbild mit der Heiligen Dreifaltigkeit für den Hochaltar der Grazer Dreifaltigkeitskirche (Abb. 10). ${ }^{31}$ Für seine Arbeit erhielt der Maler 50 Taler, ${ }^{32}$ was umgerechnet 100 Gulden entspricht. ${ }^{33}$

In den Jahren 1700 bis 1715 fertigte Johann Veit Hauckh, wie Urkunden belegen, immer wieder Arbeiten für das Stift Seckau an. ${ }^{34} 1702$ bestätigte Hauckh den Empfang von 18 Gulden für ein Bildnis des Propstes Franz Sigismund von Schrott. ${ }^{35}$ Der für dieses Porträt gezahlte Betrag lässt vermuten, dass das Gemälde wohl nur als Brustbild ausgeführt worden war.

Für ein in Auftrag von Maria Rosalia Reichsgräfin von Dietrichstein gemaltes Altarbild in der Seitenkapelle der Kapuziner-Klosterkirche in Schwanberg wurden im Dezember 1712 insgesamt 60 Gulden an Johann Veit Hauckh ausbezahlt. ${ }^{36}$

de Pomis gegründeten Maler-Confraternität in Graz, Beiträge zur Kunde steiermärkischer Geschichtsquellen, 23, 1891, S. 10-21; Marina BECK, II.36 Graz, Statuta Pictorum. Kommentierte Edition der Maler(zunft)ordnungen im deutschsprachigen Raum des Alten Reiches. 2: Esslingen bis Konstanz (Hrsg. Andreas Tacke), Petersberg 2018, S. 250-276.

31 REDL 1986 (Anm. 29), S. 12, 455-456, Kat. Nr. 7. Das Gemälde hat die Maße 293 x 180 cm.

32 Ursulinenkonvent, Graz, Chronik des Klosters der Ursulinen von 1686-1772, 1702, S. 134, zitiert nach SCHMITZ 1927 (Anm. 7), S. 36: Ihro fürstlich gnaden Rosalia Maria Eleonora Reichsfürstin von Eggenberg, ein gebohrene Fürstin von Liechtenstein. Hat ein großes bilt in Hochaltar machen lassen pr 50 Taller, so Herr Johann Veith Hauckh gemahlen. Die Dissertation von Schmitz wird bei REDL 1986 (Anm. 29) nicht erwähnt. Rochus KOHLBACH, Kirchen- und Schlösserrechnungen, s. a. (maschinenschriftlicher Nachlass), Bundesdenkmalamt, Abteilung für Steiermark, Inv. Nr. 3277, S. 267, weist darauf hin, dass Hauckh das Altarbild für 50 Taler malte, die von Rosalia Maria Eleonore Reichsfürstin von Eggenberg bezahlt wurden.

33 Ab dem Jahr 1693 galt: ein Gulden = 60 Kreuzer und ein Taler = 120 Kreuzer. Siehe dazu Alfred Francis PRIBRAM, Materialen zur Geschichte der Preise und Löhne in Österreich, 1, Wien 1938, S. 3, Anm. 4, und S. 43.

34 Siehe dazu die chronologische Übersicht zur Bau- und Kunstgeschichte des Stiftes Seckau bei Benno ROTH, Seckau. Der Dom im Gebirge. Kunsttopographie vom 12. bis zum 20. Jahrhundert, Graz-Wien-Köln 1984, S. 512513, und REDL 1986 (Anm. 29), S. 513, Kat. Nr. 150-151. Unter Dompropst Franz Sigismund von Schrott schuf der Maler einen Entwurf für ein Gemälde des 1590 verstorbenen Erzherzogs Karl II., für das er 1700 mit 55 Gulden bezahlt wurde. Quittung vom 19. Juli 1700, zitiert nach Benno ROTH, Spätbarockes Kunstschaffen unter den Seckauer Dompröpsten, Seckau 1961 (Seckauer geschichtliche Studien, 16), S. 20: /.../ daß ich En[d]sundergeschriebener Von Ihro Hochwürdt und Gnaden Herrn, Herrn Sigismundt Thumbbrosten vnd Erzpriestern zu Seggau Vor Ein Delineation des Erzherzog Carl bin bezahlt wordten mit fünffVndfünffzig Gulten. Diß bezeigt mein durchgehendt handtschrifft Vnd fertigung. dat. Graz den 19. Juli 1700. Johann Veith Hauckh, fürstl=Eggenbergerscher Hoffmaller. Siehe dazu auch ROTH 1984 (Anm. 34), S. 512, und REDL 1986 (Anm. 29), S. 514, Kat. Nr. 155. Diese erstaunlich hohe Summe, die für einen wie auch immer gestalteten Porträtentwurf ausgezahlt wurde, deutet darauf hin, dass es sich um eine ganzfigurige Darstellung des Erzherzogs gehandelt hat. Da aus den erhaltenen Quittungen nicht immer eindeutig hervorgeht, welche Arbeiten des Künstlers vergütet wurden, werden im Folgenden nur die eindeutigen Zahlungen aufgeführt.

35 Quittung vom 21. Mai 1702, zitiert nach ROTH 1961 (Anm. 34), S. 20: Mehr Ihro Hochw[ürden] u[nd] G[na]den obigen Praelathen sein Conterfee gemahlt /.../ 18 fl. Siehe dazu auch ROTH 1984 (Anm. 34), S. 512, und REDL 1986 (Anm. 29), S. 514, Kat. Nr. 156.

36 Zitiert nach KOHLBACH s. a. (Anm. 32), S. 1259: 1712 18. Dez. Johann V. Hauckh Kayl. Priv. Maller: Quit per 60 fl So ich Endts vnder schribner von Ihro Hoch Gräffl. Excellenz und Wohl gebornen Frauen Frauen Maria Rosalia Reichs graffin von Dietrich Stain gb Reichsgraffin von Herberstein (geben). / vor das altharblatl des J. Fahlentini vor die Capuziner. Ähnlich bei REDL 1986 (Anm. 29), S. 398, Anm. 57. Siehe dazu auch REDL 1986 (Anm. 29), S. 72 und S. 461, Kat. Nr. 25, sowie Joseph von ZAHN, Steirische Miscellen. Zur Orts- und Culturgeschichte der Steiermark, Graz 1899, S. 291. 
Einen außergewöhnlich hohen Preis von 350 Gulden, der wegen der monumentalen Maße des Gemäldes mehr als gerechtfertigt war, erzielte Johann Veit Hauckh für eine 1718/1719 geschaffene Himmelfahrt Mariä (Abb. 11), die für den Hochaltar der Grazer Franziskanerkirche bestimmt war. ${ }^{37}$ Der an den Künstler gezahlte Betrag ist auch im Verhältnis zu dem, was Franz Carl Remp und Hans Adam Weissenkircher für großformatige Altarbilder bekamen, durchaus angemessen, denn er liegt 50 Gulden über dem, was Remp für seine großen Altarbilder in Stift Kremsmünster (Abb. 1-2) erhielt, und 50 Gulden unter dem an Weissenkircher für das Altarbild mit den Vierzehn Nothelfern (Abb. 9) gezahlten Betrag. Es gilt auch zu bedenken, dass dem Maler Hauckh beim Abschluss des Vertrags für das Gemälde zudem ein kostenloses Begräbnis unter dem Hochaltar der Franziskanerkirche zugesichert wurde, so dass die Himmelfahrt Mariä nicht nur den Hochaltar, sondern zugleich auch das Grab des Künstlers schmückte. Ohne dieses Privileg der Grablegung im Chor der Franziskanerkirche hätte der Preis für das Altarbild wohl noch höher angesetzt werden müssen.

Auch in den folgenden Jahren arbeitete

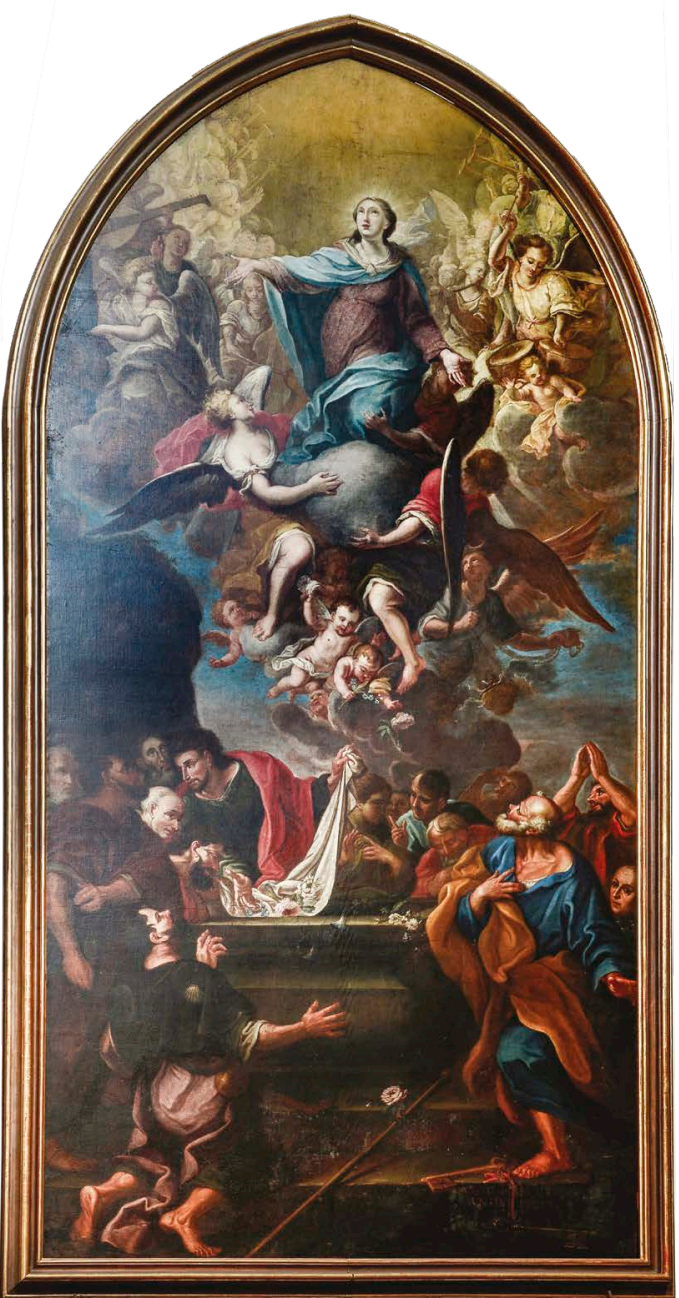

11. Johann Veit Hauckh: Himmelfahrt Mariä, 1718/1719, Wallfahrtskirche Mariatrost, Graz Hauckh für die Franziskaner. 1721 und 1722 schuf er zwei Altarbilder mit Darstellungen der hl. Barbara und der Stigmatisation des hl. Franziskus, die für die Seitenaltäre der Franziskanerkirche bestimmt waren. ${ }^{38}$ Für die beiden Gemälde

37 Erste Verhandlungen mit dem Künstler waren am 24. Juni 1718 geführt worden, der Vertrag wurde aber wohl erst am 28. Oktober 1718 unterzeichnet. Im Franziskanerarchiv Graz, Codex Nr. 4, Regestum Conventus Graecensis, Blatt 99r, findet sich unter dem Datum vom 24. Juni 1718 der Eintrag: 24. in prandio fuit D. Hauck artificiosus pictor, cum quo contractum fuit propter imaginem ad Summum Altare, und auf Blatt 99v-100r heißt es unter dem Datum vom 28. Oktober 1718: 28. In festo Simonis et Juda fuit subscriptus contractus factus cum D. Hauck de imagine pingenda ad Summum Altare /.../. Rochus KOHLBACH, Die gotischen Kirchen von Graz, Graz 1950, S. 101, gibt die erste Textstelle in der Übersetzung wieder: 1718 24. VI. Beim Frühstück war zugegen Herr Hauck, ein kunstbegabter Maler, mit dem ich den Kontrakt auf Malung des Hochaltarbildes abschloß. Das fertiggestellte Gemälde wurde am 10. Juni 1719 in den Altar eingesetzt. Zitiert nach KOHLBACH 1950 (Anm. 37), S. 102: 171910. VI. An diesem Tag alss an einem Sambstag ist das schöne und kunstreiche Altar Blatt sambt den vergultenen ramb in das Altar hineingesetzt worden. Leicht gekürzt bei REDL 1986 (Anm. 29), S. 94. Siehe dazu REDL 1986 (Anm. 29), S. 18-19, S. 94-100 und S. 464, Kat. Nr. 33. Das möglicherweise in der Breite etwas beschnittene Gemälde hat die Maße 502 x $258 \mathrm{~cm}$. Es befindet sich heute in der Grazer Wallfahrtskirche Mariatrost.

38 Zitiert nach KOHLBACH 1950 (Anm. 37), S. 102-103: Anbelangend den dermahligen Altar der hl. Barbarae ist Anno 1721 der Anfang zu bauen gemacht worden. Das Altar blat hat gemahlen der woll Edle Herr Johann Vitus von Hauck, /.../. Anbelangend den gegenüber stehenden Altar des hl. Francisci ist solcher eben auf diesen rüss 


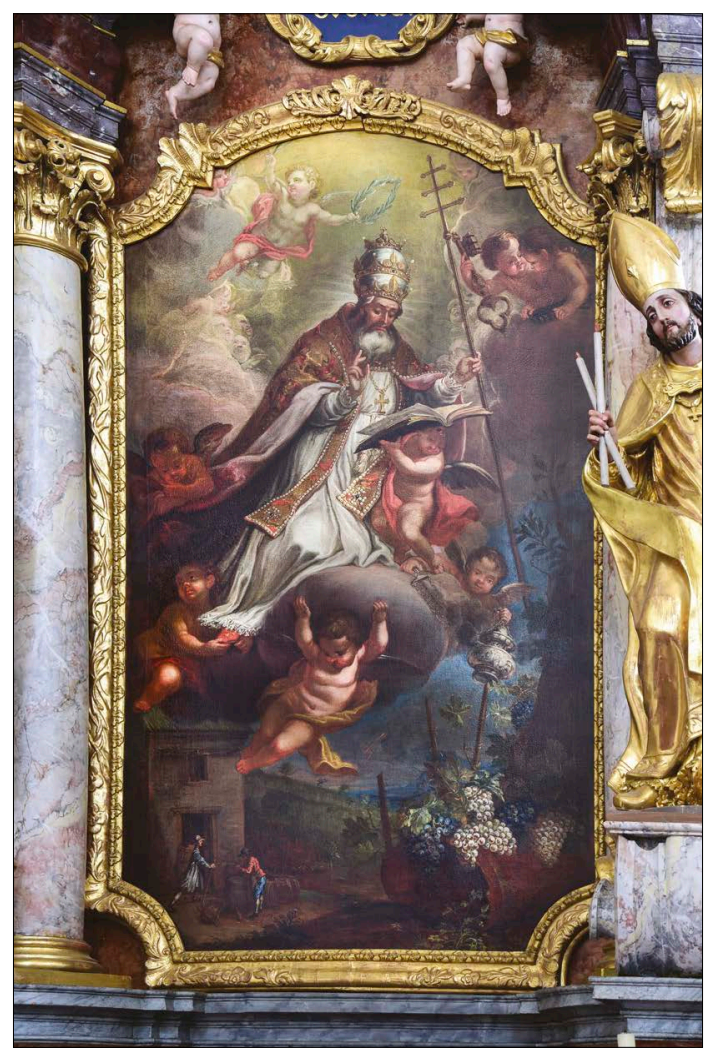

12. Johann Veit Hauckh: Der hl. Urban, 1723, Pfarrkirche, St. Andrä im Sausal

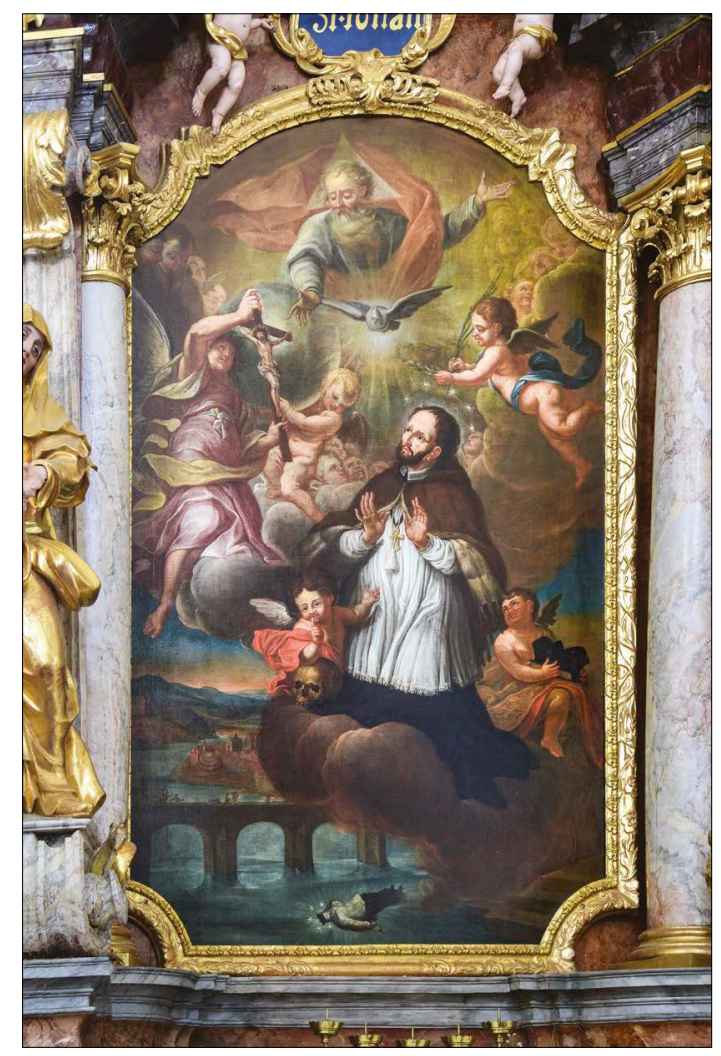

13. Johann Veit Hauckh: Der hl. Johannes Nepomuk, 1723, Pfarrkirche, St. Andrä im Sausal

wurden Hauckh am 15. November 1723 von Guardian Mauritius Steizinger insgesamt 300 Gulden ausgezahlt. ${ }^{39}$

In den Folgejahren musste Hauckh sich jedoch mit weitaus geringeren Beträgen als Honorar für seine Altarbilder zufriedenzugeben. So bestätigte er im Mai 1725 den Erhalt von 150 Gulden für zwei bereits 1723 geschaffene Altarbilder mit dem hl. Urban und dem hl. Johannes Nepomuk (Abb. 12-13) in der Kirche St. Andrä im Sausal. ${ }^{40}$ Sofern Hauckh nicht bereits zuvor eine Anzahlung für die beiden Altarbilder erhielt, die in den Dokumenten nicht aufscheint, wurde er mit 75 Gulden für ein Altarbild in St. Andrä vergleichsweise schlecht bezahlt. Der niedrige Preis kann nicht allein

gleichförmig gemacht worden, durch das Jahr 1721. Die beyde Altar Bläter als S. Francisci und S. Johannis Capistrani seynd ebenfalls gemahlen worden von dem Edlen Herrn von Hauck /.../. Siehe dazu REDL 1986 (Anm. 29), S. 19 und S. 464-465, Kat. Nr. 34, und S. 513, Kat. Nr. 152. Das von Hauckh signierte und 1722 datierte Gemälde mit der Stigmatisation des hl. Franziskus befindet sich im Franziskanerkloster. Es hat die Maße 326 x $158 \mathrm{~cm}$. Das in den Maßen wohl identische Gemälde mit der hl. Barbara ist verschollen. Zu den Oberbildern im Auszug der beiden Altäre, einem hl. Josef von Weissenkircher und dem von Hauckh geschaffenen hl. Johannes von Capistran siehe KOHLBACH 1950 (Anm. 37), S. 108-109.

39 REDL 1986 (Anm. 29), S. 19.

40 Zitiert nach KOHLBACH s. a. (Anm. 32), S. $320: 1725$ 10. Mai Johann Veit Hauckh Hof vnd Laa: Mahler: Wegen in selbiges Gottshauss 2 gemahlten Altar Bilter H. Urban und Francisci Xaveri 150 fl. richtig erhalten. Gekürzt und leicht verändert bei REDL 1986 (Anm. 29), S. 24. Die Benennung des hl. Franz Xaver ist falsch, denn auf dem zweiten Altarbild ist der hl. Nepomuk dargestellt. Siehe dazu REDL 1986 (Anm. 29), S. 24 und S. 468, Kat. Nr. 42 und 43. Die beiden Altarbilder haben die Maße 236 x $135 \mathrm{~cm}$. 
mit der geringeren Größe der beiden Altarbilder erklärt werden, sondern ist möglicherweise auch auf ein Preisgefälle zwischen der Landeshauptstadt und dem Umland, also dem Zentrum und der Peripherie, zurückzuführen.

Besser vergütet wurde das Altarbild mit der Anna Selbdritt sowie den hll. Josef und Joachim (Abb. 14), das Placidius Mally, der Abt von Stift Rein, beim Künstler in Auftrag gegeben hatte und das 1731 fertiggestellt war. ${ }^{41}$ Das mittelgroße Gemälde kostete 104 Gulden. ${ }^{42}$

Bereits 1715 hatte der Maler für zwei Gemälde in der Grazer St. Leonhardskirche insgesamt 150 Gulden erhalten. ${ }^{43} \mathrm{Da}$ es sich um zwei Bilder für einen Vierzehn-Nothelfer-Altar handelte, ist anzunehmen, dass Hauckh ein mittelgroßes, daher teureres Altarbild sowie ein preiswerteres Oberbild angefertigt hatte. ${ }^{44}$

Auch 1730 soll der Maler für ein Altarbild mit den Vierzehn Nothelfern (Abb. 15) und ein weiteres mit dem hl. Donatus, die sich an den Altären der Seitenkapellen der Pfarrkirche St. Veit in Passail befinden, 150 Gulden erhalten haben. ${ }^{45}$ Wahrscheinlicher ist aber, dass mit den

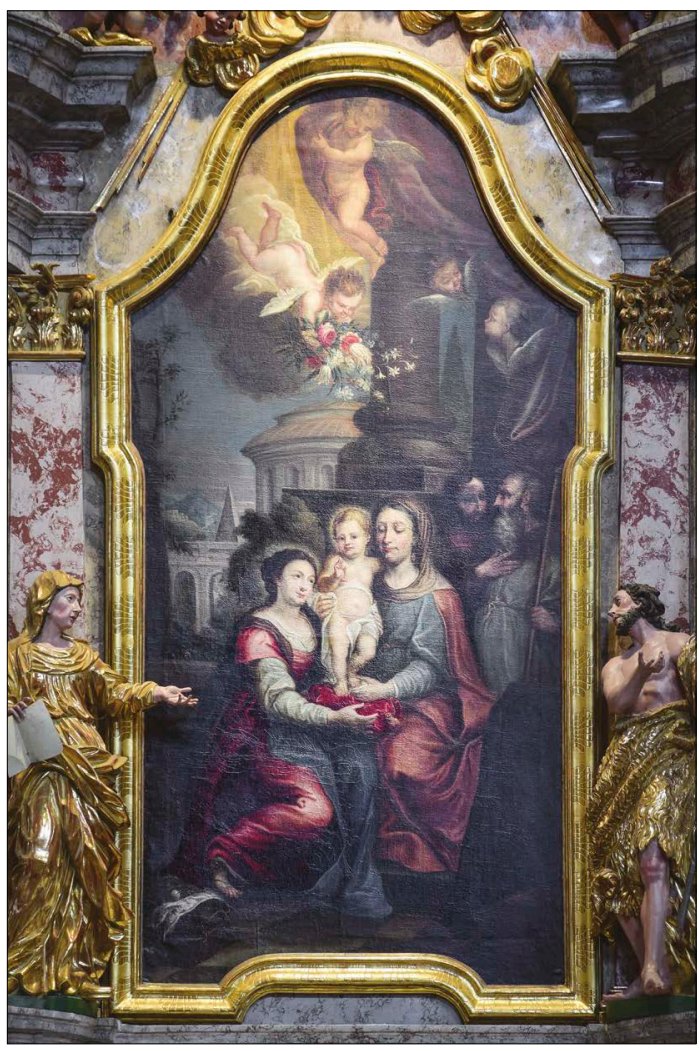

14. Johann Veit Hauckh: Anna Selbdritt mit den hll. Josef und Joachim, 1731, Stiftskirche, Zisterzienserstift Rein 150 Gulden nicht nur diese beiden Gemälde,

41 Siehe dazu REDL 1986 (Anm. 29), S. 25-26 und 470-471, Kat. Nr. 48. Das signierte und datierte Gemälde hat die Maße 284 x $137 \mathrm{~cm}$.

42 Calendereintragung des Abtes von Stift Rein am 21. Februar 1732, zitiert nach KOHLBACH s. a. (Anm. 32), S. 963: Eodem bezahle Herrn Haukh vor das Altar Blath in den neuen Anna Altar 25 Ducaten. Diese Zahlungsanweisung findet sich auch im handschriftlichen Nachlass von Rochus Kohlbach, Diözesanarchiv Graz-Seckau (DAG), Stift Rein, III. Calender-Eintragungen, s. p. Hier ist im Anschluss an die 25 Ducaten auch der Wert in Gulden (104 fl) vermerkt. Ähnlich bei REDL 1986 (Anm. 29), S. 26.

43 DAG, Pfarrarchiv St. Leonhard, zitiert nach KOHLBACH 1950 (Anm. 37), S. 183: 1715 den 8. Aprill Herrn Hauckhen Mallern vor 2 Blätter zum 14 Notthelffern altar $150 \mathrm{fl}$. Ähnlich (Blödter statt Blätter) bei KOHLBACH s. a. (Anm. 32), S. 181. In abweichender Schreibweise bei REDL 1986 (Anm. 29), S. 229.

44 Siehe dazu KOHLBACH 1950 (Anm. 37), S. 183-184, der davon ausgeht, dass das Oberbild verloren ist und es sich bei dem urkundlich erwähnten Altarbild nicht um das in St. Leonhard erhaltene Gemälde mit dem Mariahilfer Gnadenbild, dem hl. Leonhard und anderen Heiligen handelt. Dem folgt letztlich auch REDL 1986 (Anm. 29), S. 229, da die neben dem Titelheiligen Leonhard dargestellten vier Apostel nicht zu den Nothelfern gehören. Ganz grundsätzlich kann angemerkt werden, dass auf dem Altarbild in St. Leonhard keine 14 Nothelfer dargestellt sind, der Zahlungsbeleg also nicht mit dem in St. Leonhard erhaltenen Altarbild verbunden werden kann. Zum Mariahilfer Gnadenbild mit Heiligen siehe auch REDL 1986 (Anm. 29), S. 480-481, Kat. Nr. 72.

45 DAG, Gedenkbuch der Pfarre Passail, 1730, zitiert nach KOHLBACH s. a. (Anm. 32), S. 859: Der Mahler Veit Hauk erhielt für gemalte Bilder $150 \mathrm{fl}$. Eines davon ist das Bild am 14 Nothelferaltar, das andere (am) Donatialtar und Patrizibild. Leicht verändert bei REDL 1986 (Anm. 29), S. 25. Siehe dazu REDL 1986 (Anm. 29), S. 138-143 und S. 469-470, Kat. Nr. 46 und 47. Laut REDL 1986 (Anm. 29), S. 469-470, sind die Gemälde mit den 14 Nothelfern und dem hl. Donatus links unten mit „J V Hauck 1731“ signiert und datiert. Unklar bleibt, wieso der Maler bereits ein Jahr zuvor für die beiden Gemälde bezahlt wurde. 


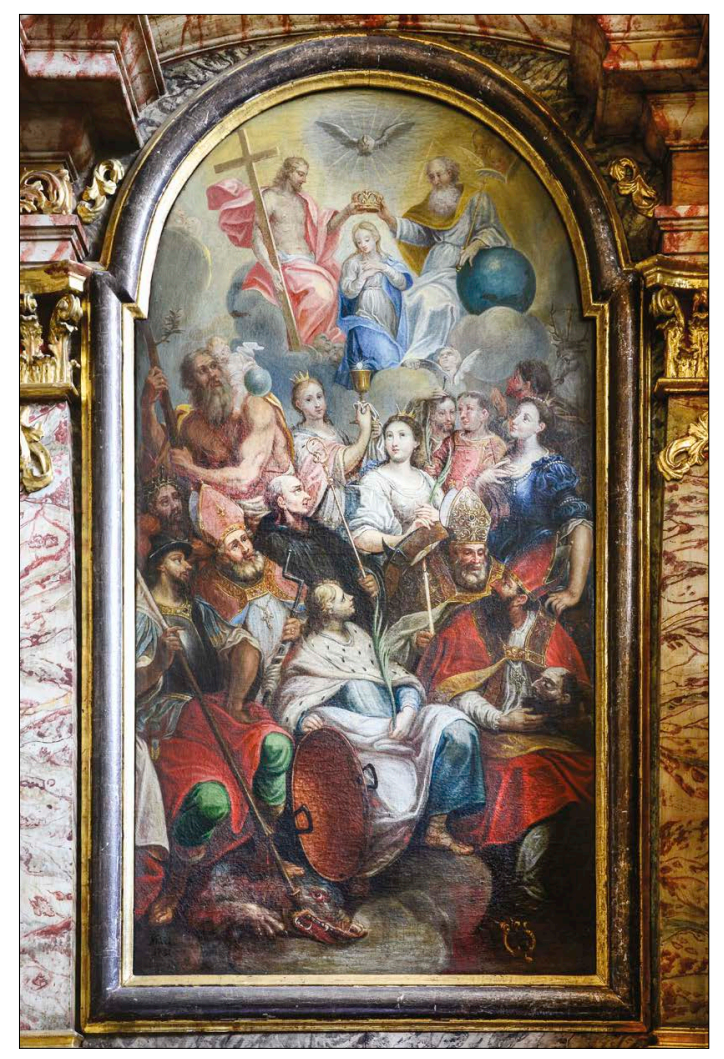

15. Johann Veit Hauckh: Die Vierzehn Nothelfer, 1731, Pfarrkirche des Hl. Veit, Passail sondern noch ein drittes Altarbild mit dem hl. Veit vergütet wurde. ${ }^{46}$ Demzufolge hätte sich Hauckh mit 50 Gulden für ein Altarbild zufriedengeben müssen.

Eine Deutung der erhaltenen Dokumente wird auch dadurch erschwert, dass Johann Veit Hauckh dem Pfarrer von Passail zuerst das Angebot unterbreitete, als Ersatz für das alte Hochaltargemälde mit dem Letzten Abendmahl ein neues Altarbild seines Namenspatrons, des heiligen Veit, zu malen, und zwar für den halben Preis von insgesamt 150 Gulden. Erst nach langem Zureden soll der Maler bereit gewesen sein, für dieses Geld auch das Oberbild mit einem Letzten Abendmahl und eine hl. Barbara für den Barbara-Altar zu malen. ${ }^{47}$ Weitere 1730 und 1731 geleistete Zahlungen im Zusammenhang mit den Gemälden für die Pfarrkirche in Passail lassen darauf schließen, dass Hauckh mindestens drei Gemälde für Passail geschaffen hat. ${ }^{48}$ Eine abschließende Deutung ist wegen der Uneindeutigkeit der erhaltenen Dokumente wohl nicht möglich. Ob Johann Veit Hauckh wirklich der Meinung war, dass ein von ihm geschaffenes mittelgroßes Altarbild 300 Gulden wert sei, darf bezweifelt werden. Sein Angebot, das Hochaltarbild zum halben Preis zu malen, entsprach vermutlich eher dem, was eine Pfarrkirche in der Steiermark an Kosten für ein solches Gemälde aufbringen konnte. Wenn Hauckh schließlich noch weitere Gemälde

46 REDL 1986 (Anm. 29), S. 143 und S. 407-408, Anm. 162, vermutet unter Bezugnahme auf KOHLBACH s. a. (Anm. 32), S. 859, dass mit den 150 Gulden insgesamt drei Gemälde von Hauckh bezahlt wurden, von denen das Gemälde des Schutzpatrons, also das eigentliche Hochaltarbild mit dem hl. Veit, verschollen ist, nachdem es 1781 durch das neue, von Joseph Adam Mölk geschaffene Altarbild mit der Darstellung des Letzten Abendmahls ersetzt worden war. Wegen des geringen Preises von nur 50 Gulden pro Bild sei auch der Anteil Hauckhs, der in den Jahren 1728 bis 1730 mit der Ausführung großer Werke für die Hofkammer beschäftigt war, an diesen Gemälden gering.

47 DAG, Gedenkbuch der Pfarre Passail, 1730, zitiert nach KOHLBACH s. a. (Anm. 32), S. 860: 1730 12. März Herr Hauckh hatte sich dem Pfarrer gegenüber mit Schreiben dieses Datums erboten, 3 Blötter per $150 \mathrm{fl}$. mit guetten beständigen Farben der Kunst nach zu mahlen. (Brief verloren) Der Pfarrer berichtet darüber dem Bischof: Habe Euer Fürstl. Gnaden gehorsambist zu berichten, das in hiesiger Pfarr Kirch der hl. Veit schuz Patron Seye, welcher in einen Kleinen Blat auf der Hohe (Oberbild des Hochaltars?) gemahlen ist, das grosse Altar Blatt ist das abentmahl, anstat dessen wegen sehr villen schricken ein Neyes vonnethen wäre. Herr Veit Hauckh Kayl. Hoff Cammer Maller in Grätz hat sich angetragen, sein H. Namens Patron zu Ehren den Hl. Veit im gresseren Blat mit guetten bestendigen Farben aufs Beste der Kunst gemess vmb halbes gelt nemblich um $150 \mathrm{fl}$ zu mahlen; auf Villes zuesprechen hat er entlich versprochen, vmb dieses Gelt noch 2 andere Blötter, nemblich das abentmahl in der Höhe und ins Barbara altar die hl. Barbaram zu mahlen, wie solches auf seinem Brieff zu sehen /.../ Kirche bei guten Mitteln, es wurde gesammelt für die Marbolierung des Hochen Altar. Bitte um Konsens / Bischöflicher Consens am 4. April 1730 gegeben.

48 Aus den Kirchenrechnungen zitiert nach KOHLBACH s. a. (Anm. 32), S. 862: 1730 Herrn Hauckhen an 3 Bildern vnterdessen zalt $100 \mathrm{fl} /$ Herrn Hauckhen auff die 3 Bilder das ybrige $5 \mathrm{fl}$ und 1731 Herrn Haucken Mallern in Gräz die altar Blat des neuen Altar $90 \mathrm{fl}$. 
für eine Bezahlung in Höhe von insgesamt 150 Gulden lieferte, dann war er bei Verhandlungen um die Vergabe von Aufträgen durchaus zu Zugeständnissen bereit.

Johann Veit Hauckh betätigte sich auch als Bildnismaler. In einem Schreiben an die Innerösterreichische Hofkammer, das am 8. Mai 1713 dort eintraf, bat er um die Auszahlung von 75 Gulden für drei Porträts der Kaiser Leopold I., Joseph I. und des regierenden Kaisers Karl VI. ${ }^{49}$ In einem Antwortschreiben vom 8. Mai 1713 wurde dem Innerösterreichischen Hofpfennigamt der Auftrag für die Auszahlung dieser Summe erteilt. ${ }^{50}$ Der vergleichsweise geringe Gesamtbetrag für drei Porträts habsburgischer Kaiser ergibt sich aus der Tatsache, dass die beiden verstorbenen Kaiser in halber Figur wiedergegeben sind, während es sich bei dem im Format größeren Gemälde Karls VI. um ein Kniestück handelt. ${ }^{51}$ Außerdem waren diese Gemälde für das Kapuzinerkloster in Karlobag in Kroatien bestimmt, wo sie sich noch heute befinden. Der vergleichsweise geringe Preis für diese drei Porträts könnte also erneut auf eine andere, niedrigere Preisgestaltung von Gemälden, die für die Peripherie des Reiches bestimmt waren, zurückzuführen sein.

Unter dem Datum vom 13. Mai 1723 findet sich in den Hofkammerakten die Anweisung zur Auszahlung von 158 Gulden an den Hofmaler Veit Hauckh für ein Porträt des Kaisers Karl VI. ${ }^{52}$ Aufgrund der Höhe des an den Maler ausgezahlten Betrags dürfte es sich bei dem heute verschollenen Gemälde um ein lebensgroßes Bildnis gehandelt haben.

Ein letzter Zahlungsbeleg gibt Auskunft über die Kosten von kleinformatigen Gemälden. Für zwölf im Jahr 1709 geschaffene, kleine ovale Brustbilder von Heiligen, ${ }^{53}$ die an der Grazer Domkanzel

49 Steiermärkisches Landesarchiv (StLA), Hofkammerakten, 1713-V-15, K 1393: /.../ die 3 Bildtnusßen deren Khay[s]l:[ichen] Mayestetten alß mildtseelligsten gedechtnusßen Leopoldi, et Josephi primi dan des jezt Regirenten Khaysers Caroli 6:ti /.../ alß habe ich meiner möglichkheith gemasß solliche arbeith Vollzogen, Und will demnach soliche 3 bildnusßen hiermit in Unterth[än]igkheith überraicht haben. Euer hochgräffl:[ich] Exell:[enz] g[na]d:[en] und g[na]d:[en] Unterth[än]igl:[ich] gehor:[samst] bittend, selbe belieben mir gedachte $75 \mathrm{fl:}$ in g[na]d:[en] anzuschaffen, damit mir sodann jene in dem Khay[ser]l:[ichen] HoffPfennig ambt gegen quittung bezalt werden mögen. /.../ Johann Veith Hauckh Maller. Kürzer und geringfügig anders zitiert bei REDL 1986 (Anm. 29), S. 15. Siehe dazu REDL 1986 (Anm. 29), S. 514, Kat. Nr. 157 a, b und c.

50 StLA, Hofkammerakten, 1713-V-15, K 1393: Den 8. Maij 1713. /.../ dem Johann Veith Hauckh maller alhier /.../ die accordierten $75 \mathrm{fl}$. für die 3 bildnusßen deren Kay[ser]l:[ichen] Mayeßtetten alß mildselligstes gedechtnuß Leopoldi, et Josephi primi dan des Jezt regierenden Kaysers Caroli 6ti so Er ad eorum effigiem verfasßet, /.../ bezallen zu lassen /.../. Die Anweisung zur Zahlung von 75 Gulden vom 8. Mai 1713 an den Maler Johann Veit Hauckh ist auch im Expeditum in HoffCammer Sachen, 1713 unter dem Datum vom 15. Mai vermerkt: StLA, Innerösterreichische Hofkammer, Rep. 1713: Maius 15 Daß I:[nner] Ö:[stererichische] HoffPfe[nnig] ambt solle dem Johann Veith Hauckh Mahler für 3. Kay[ser]l[iche] contrafèe 75 fl. bezallen, und soliche bilder denen P: P: Capucinern Zu Carlwag eheistens überschickhen. Die Porträts waren für das Kapuzinerkloster in Carlwag bestimmt und sollten dahin überstellt werden. REDL 1986 (Anm. 29), S. 514, Kat. Nr. 157 a, b und c, geht davon aus, dass die Gemälde für den Kapuzinerorden in Kalwang in der Steiermark bestimmt waren. Es gab aber in Kalwang nie ein Kapuzinerkloster. Mit Carlwag oder Carlwaag ist vielmehr Karlobag in Kroatien gemeint, dessen Kapuzinerkloster 1708 durch die steirische Ordensprovinz gegründet wurde. Die Weihe der Klosterkirche auf den hl. Josef, den Schutzpatron der Steiermark, erfolgte 1714. Siehe dazu Lexikon Capuccinum. Promptuarium historico-bibliographicum Ordinis Fratorum Minorum Capuccinorum (1525-1950), Rom 1951, Sp. 897.

51 Die Gemälde befinden sich noch im Kapuzinerkloster in Karlobag. Die Porträts der verstorbenen Kaiser Leopold I. und Josef I. sind 108 x $83 \mathrm{~cm}$ bzw. 108 x $87 \mathrm{~cm}$ groß, das Porträt Karls VI. misst 175 x $123 \mathrm{~cm}$. Siehe dazu Josipa ALVIŽ, Slikarstvo XVII. i XVIII. stoljeća u kapucinskim crkvama i samostanima u Hrvatskoj/Painting of the $17^{\text {th }}$ and $18^{\text {th }}$ Century in the Capuchin Churches and Monasteries in Croatia, 2, Zagreb 2015 (ungedruckte Dissertation), S. 361-362, Kat. Nr. 8-10.

52 StLA, Hofkammerakten, 1723: /.../ den Hoffmaller Veith Hauckh wegen zur Hochansehl:[ichen] geh[aim]ben Stöll Verförtigten Kay[serliche] Contrafait 158 fl. bezallen zu lassen. Den 13. May. Leicht verkürzt bei REDL 1986 (Anm. 29), S. 22. Siehe dazu REDL 1986 (Anm. 29), S. 514, Kat. Nr. 159.

53 Am Kanzelaufgang und am Kanzelkorb befinden sich die hll. Ignatius von Loyola, Franz Xaver und die vier 
angebracht sind, erhielt Johann Veit Hauckh 102 Gulden ${ }^{54}$ also achteinhalb Gulden pro Bild.

Außerdem genoss Johann Veit Hauckh, der 1714 zum Hofmaler ernannt worden war, die Privilegien der hofbefreiten Künstler und erhielt eine jährliche Dotation von „drei Furder Salz“. ${ }^{55}$

Erheblich schwieriger zu fassen und zu beurteilen sind die Zahlungen, die der Vorauer Stiftsmaler Johann Cyriak Hackhofer (1675-1731) als Lohn für die von ihm geschaffenen Altarbilder erhielt. Der seit 1708 im Stift Vorau und den dazu gehörenden Pfarreien tätige Maler war wie Franz Carl Remp im Jahr 1675 geboren worden.

Vergleichsweise gut dokumentiert sind die Kosten für den in den Jahren 1715 bis 1716 geschaffenen Hochaltar in der Pfarrkirche in Mönichwald. Für die architektonische und skulpturale Ausstattung des Altars wurden insgesamt 1003 Gulden aufgebracht. Davon gingen 100 Gulden an den Maler Johann Cyriak Hackhofer, 222 Gulden an den Tischler Remigius Horner und 125 Gulden an den Bildhauer Andreas Schellauf. Insgesamt 524 Gulden, also deutlich mehr als die Hälfte der Kosten, wurden dem Vergolder ausbezahlt. ${ }^{56}$ Der Maler erhielt die 100 Gulden jedoch nicht für das Altarbild und das dazugehörige Oberbild, sondern für die farbige Fassung des Altars und der Figuren, wobei er nicht für die gesondert vergütete Vergoldung verantwortlich war. ${ }^{57}$ Für das von Hackhofer geschaffene, signierte und datierte Altarbild mit den Hll. Petrus und Paulus vor der Madonna sowie einen Gnadenstuhl auf dem Oberbild des Altars, die beide erst 1722 fertiggestellt wurden, ${ }^{58}$ haben sich jedoch keine Rechnungsbelege erhalten, weshalb ein Vergleich mit anderen Altarbildern nicht möglich ist.

Drei von Hackhofer für die Pfarrkirche in Friedberg geschaffene und nicht näher bezeichnete Fastenbilder wurden 1721 mit insgesamt 30 Gulden bezahlt. ${ }^{59}$ Der geringe Preis von zehn Gulden pro Bild erklärt sich dadurch, dass Fastenbilder, die in der Fastenzeit vor die Altarbilder gehängt wurden und häufig mit Passionsszenen versehen waren, ${ }^{60}$ in der Herstellung nicht so aufwendig wie

Kirchenväter, an der Rückwand die Apostel Petrus und Paulus und am Schalldeckel die vier Evangelisten. Die ovalen Gemälde haben die Maße von etwa 70 x 40 und 55 x 40 cm. Siehe dazu REDL 1986 (Anm. 29), S. 60-70 und S. 458-460, Kat. Nr. 12-23.

54 DAG, XX-C-10, Domrechnungsbuch, Pergamenthandschrift, s. p.: 1710 30. January /.../ Alteri Pictori Hauk pro 12 Iconibus SS. Apost. Petri, et Pauli, quatuor Evangelistarum, et quatuor Doctorum Ecclesiae: S. Ignatij, S. Franc. Xaverij, et S. Spiritus in Superiori parte Cathedrae - 102 fl. Ähnlich bei REDL 1986 (Anm. 29), S. 398, Anm. 55. Siehe dazu REDL 1986 (Anm. 29), S. 15, S. 60-70 und S. 458-460. KOHLBACH s. a. (Anm. 32), S. 15 vermerkt: 1710 30. Jänner Dem Maler Hauck für 12 Kanzelbilder $102 \mathrm{fl}$.

55 REDL 1986 (Anm. 29), S. 16-17, mit Verweis auf Josef WASTLER, Steirisches Künstler-Lexicon, Graz 1883, S. 42.

56 Pfarramt Mönichwald, Verzaichnuss was zur gänzlicher Erbauung des löbl. Gottshaus alhier ad SS. Apostolorum Petrum et Paulum in Mönichwald inner denen 2 Jaren 1715 und 1716 verwendtet wordten wie folgt, zitiert nach Ferdinand HUTZ, Der Hochaltar von Mönichwald und seine Künstler, Blätter für Heimatkunde, 69, 1985, S. 84: Zu Aufrichtung deß Hochaltar / Erstlich den Herrn Hakhoffer 100 - / Herrn Remigi, Tischler 222 - / Herrn Schellauf, Bildthauer 125 - / Mehr vor die 6 Engl 20 - / Den Gäbriel 3 - / Mehr vor die Ross herein 5 - / Herrn Vergolter in allen 524 - / Wegen des Tabernäkhl auch 4 - / Summä 1.003. In Auszügen und geringfügig anders zitiert bei Christine WEEBER, Der Vorauer Stiftsmaler Johann Cyriak Hackhofer: 1675-1731, Graz 1987 (ungedruckte Dissertation), S. 274, Qu 9. Siehe dazu auch WEEBER 1987 (Anm. 56), S. 258-260.

57 WEEBER 1987 (Anm. 56), S. 259.

58 WEEBER 1987 (Anm. 56), S. 334-335, Ö 66 und Ö 67. Das Altarbild hat die Maße 330 x 196 cm, das vierpassförmige Oberbild misst ca. 150 x $150 \mathrm{~cm}$.

59 Pfarramt Friedberg, Rechnungsbuch 1710-1751, zitiert nach KOHLBACH s. a. (Anm. 32), S. $421: 1721$ Vor 3 fastenbilder den Herrn Hackhoffer /.../ 30 fl. Ähnlich bei WEEBER 1987 (Anm. 56), S. 276, Qu 14.

60 Zu Fastenbildern oder Fastentüchern siehe Johannes H. EMMINGHAUS, Fastentuch, Reallexikon zur Deutschen Kunstgeschichte, 7, München 1979, Sp. 826-848, und Joseph BRAUN, Die liturgischen Paramente in Gegenwart und Vergangenheit. Ein Handbuch der Paramentik, Freiburg 1924², S. 233-236. 
die etwa gleich großen Altarbilder gearbeitet waren, sondern ohne Grundierung auf die Leinwand gemalt wurden.

Ähnliches gilt für drei 1728 von Hackhofer geschaffene Antependien, für die er insgesamt zwölf Gulden erhielt. ${ }^{61} \mathrm{Da}$ in der Rechnung weder die Größe der Antependien noch die Motive oder die Art der Herstellung dokumentiert wurden und sich Antependien in ihrer Funktion von Altarbildern unterscheiden, ist auch in diesem Fall ein unmittelbarer Vergleich mit von Hackhofer oder anderen Künstlern geschaffenen Gemälden nicht möglich.

Schließlich erhielt der Maler 1729 für das Gemälde eines hl. Johannes Nepomuk sowie für fünf weitere Bilder in der Pfarrkirche von Hartberg, aber auch für zwei bei den Stadttoren errichtete Pyramiden und ein Portal vor der Kirchentür 53 Gulden und 23 Kreuzer. ${ }^{62}$ Die Gemälde und Pyramiden sowie das Portal waren Teil der Festdekoration, die anlässlich der Feier der Heiligsprechung des Johann Nepomuk am 19. März desselben Jahres in der Stadt errichtet worden war. ${ }^{63}$ Auch in diesem Fall sind die Angaben zu den Gemälden zu wenig konkret, um Vergleiche mit anderen Werken anstellen zu können. Außerdem handelte es sich um ephemere Kunstwerke, die in der Qualität ihrer Ausführung nicht mit Altarbildern und anderen Gemälden verglichen werden können.

Ebenso unspezifisch sind die Angaben zu den Arbeiten, die Hackhofer bereits zehn Jahre zuvor in der Wallfahrtskirche Maria Hasel in Pinggau ausgeführt hatte. Für die Ausgestaltung von Teilen der Kirche mit Fresken sowie die farbige Fassung der skulptierten Kreuzabnahmegruppe erhielt Hackhofer am 10. Oktober 1719 noch ausstehende 99 Gulden zu bereits gezahlten 101 Gulden. Dazu kamen noch einmal acht Gulden für Altäre und Antependien in der benachbarten Brunnenkapelle sowie vier Gulden für ein Kruzifix in der Sakristei. Außerdem wurden für den 55 Tage währenden Aufenthalt Hackhofers sowie eines Gesellen insgesamt 40 Gulden Kostgeld ausgezahlt. ${ }^{64}$ Die insgesamt 200 Gulden für die 1718 datierten und signierten Fresken im Gewölbe der Vierung und an den Wänden der Seitenarme der Wallfahrtskirche sowie die Fassung der fünffigurigen Kreuzabnahmegruppe und wohl auch der vier Figuren vom Kreuzigungsaltar ergeben nur einen Richtwert für die Kosten von Freskomalerei im ersten Drittel des 18. Jahrhunderts. Auch die acht Gulden für Altäre und Antependien in der benachbarten Brunnenkapelle können nicht für einen Vergleich mit Altarbildern herangezogen werden, weil sich in dieser Kapelle nur eine in Freskotechnik gemalte architektonische Rahmung für das geschnitzte und farbig gefasste Bild der Schmerzhaften Muttergottes befindet. Anstelle der im Dokument erwähnten Altäre gibt es nur eine gemalte Nischenrahmung für das skulptierte Altarbild, und über Größe, Art und Aussehen

61 Pfarrarchiv Hartberg, Kirchenrechnungen, zitiert nach KOHLBACH s. a. (Anm. 32), S. 523: 1728 Dem H: Hackhoffer Maller zu Vorau vor 3 Antipendi 12 fl. Ähnlich, aber ohne die genaue Angabe des Jahres bei WEEBER 1987 (Anm. 56), S. 277, Qu 18.

62 Pfarramt Hartberg, Rechnungsbuch 1729, zitiert nach WEEBER 1987 (Anm. 56), S. 279, Qu 23: Herrn Hackhofer für $1 \mathrm{Hl}$. Nepomuk und 5 andere Bilder 2 Pyramiden bei den Stadttoren und 1 Portal vor der Kirchentüre $53 \mathrm{fl} 23 \mathrm{kr}$.

63 Johannes SIMMLER, Die Geschichte der Stadt, der Pfarre und des Bezirkes Hartberg, Hartberg 1914, S. 378.

64 Aus einem nicht mehr nachweisbaren Rechnungsbuch im Pfarramt Friedberg, betreffend Maria Hasel in Pinggau, zitiert nach KOHLBACH s. a. (Anm. 32), S. 882-883: 1719 10. Oktober Dem Herrn Johann Cyriac Hackhoffer mahlern wegen des neu aufgerichteten Altar, die abnehmung Christi zu fassen, auch die ganze Capellen samt dem mittern Khirchen gewölb accordierter Massen über die vorhin empfangenen 101 den übrigen Rest per 99 fl bezahlt, dann nochmallen wegen des gemahlten altärl und Antependien in der Prun Capellen $8 \mathrm{fl} /$ Cost als 55 täge vor den Herrn Hackhoffer und seinen gesöllen $40 \mathrm{fl}$. / Vor das Cruzifix in der Sacristey Herrn Hackhoffer $4 \mathrm{fl}$. Ähnlich bei WEEBER 1987 (Anm. 56), S. 275-276, Qu 13. Zu Hackhofers Arbeiten in Maria Hasel siehe WEEBER 1987 (Anm. 56), S. 196-198, S. 273-277, Qu 7, 10-11 und 16 sowie S. 355-357, F 13, zu den Arbeiten in der zur Kirche gehörenden Brunnenkapelle siehe WEEBER 1987 (Anm. 56), S. 214 und S. 357-358, F 14. 


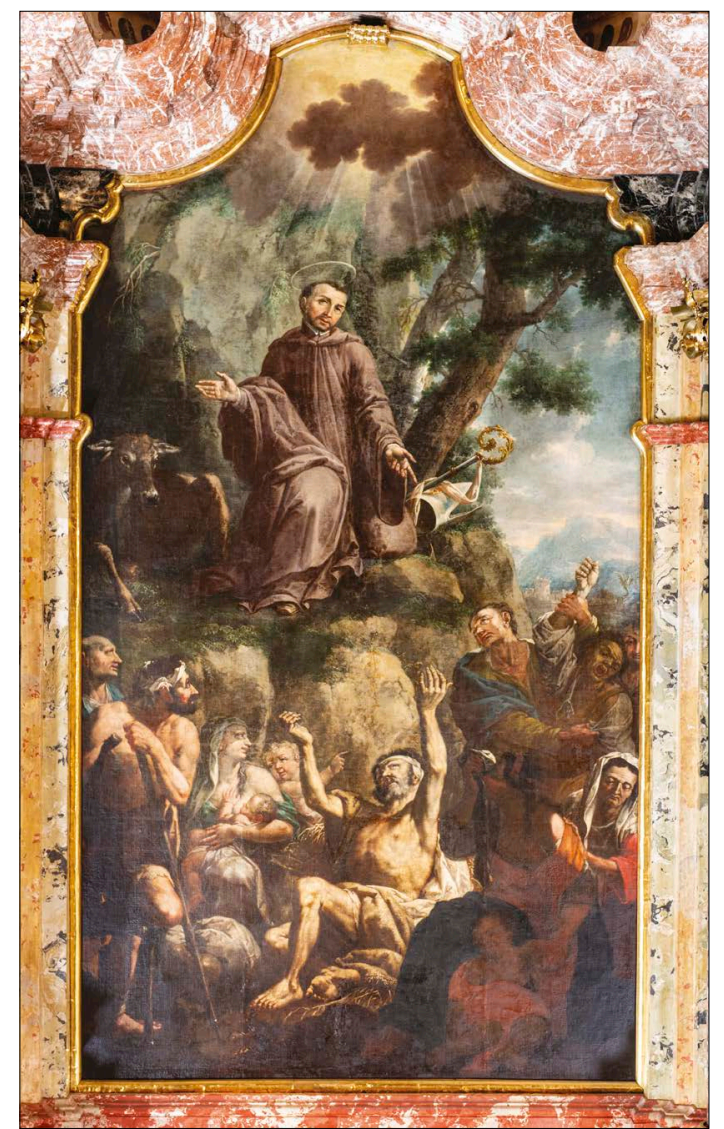

16. Franz Ignaz Flurer: Der hl. Ägidius mit Hilfesuchenden, 1733, Dom, Graz des oder der heute verlorenen Antependien sowie des Kruzifixes in der Sakristei der Wallfahrtskirche können keine näheren Angaben gemacht werden. Möglich ist, dass die vier Gulden für die farbige Fassung eines geschnitzten Kruzifixes ausgezahlt wurden.

Zu den Kosten der von Franz Ignaz Flurer (1688-1742) geschaffenen Gemälde sind einige Angaben überliefert. Wie zuvor bereits Franz Carl Remp war auch der aus Augsburg in die Steiermark eingewanderte Franz Ignaz Flurer ab etwa 1720 für Ignaz Maria Graf von Attems tätig. Nach dem Tod seines Förderers blieb der Maler weiterhin in Graz. ${ }^{65}$

Für den Grazer Dom schuf Flurer in den Jahren 1731 bis 1733 das Hochaltarbild mit der Darstellung des Hl. Ägidius mit Hilfesuchenden (Abb. 16) sowie die beiden im Format kleineren Gemälde Der hl. Ägidius und der Westgotenkönig Wamba (Abb. 17) und Der hl. Ägidius reicht einem Armen sein Gewand (Abb. 18), die seitlich des Hochaltars an den Wänden des Chores angebracht sind. ${ }^{66}$ Das Hochaltarbild wurde nach seiner Vollendung im Jahre 1733 mit 400 Gulden bezahlt, für die beiden den Altar flankierenden Gemälde erhielt Flurer im selben Jahr insgesamt 100 Gulden ${ }^{67}$ Mit 50 Gulden für ein jedes der beiden seitlichen Gemälde war die Arbeit des Künstlers im Vergleich zu den 400 Gulden für das Hochaltarbild vergleichsweise schlecht bezahlt. Auch ein Vergleich mit den 24 Gulden, die der Maler bereits im Mai 1730 für seinen Entwurf des Hochaltargemäldes erhalten hatte, ${ }^{68}$ fällt deutlich zu Ungunsten der beiden Seitenbilder aus.

65 Ulrike KRAUS-MÜLLER, Franz Ignaz Flurer (1688-1742), 1-2, Graz 1981 (ungedruckte Dissertation), 1, S. 3-9, und Ulrike KRAUS-MÜLLER, Franz Ignaz Flurer (1688-1742). Ein Barockmaler in der Steiermark (Hrsg. Wilhelm Steinböck), Stadtmuseum Graz, Graz 1982, S. 8-14.

66 KRAUS-MÜLLER 1981 (Anm. 65), 1, S. 16-19, und 2, S. 8-9, Ö 9-Ö 11, sowie KRAUS-MÜLLER 1982 (Anm. 65), S. 26 und 62, Kat. Nr. 9 und 10. Das Hochaltarbild hat die Maße 520 x 286 cm, die seitlichen Gemälde messen $258 \times 174,5 \mathrm{~cm}$ und $256,5 \times 174,5 \mathrm{~cm}$.

67 StLA, Graz-Stadt, K. 137, H. 792, Hand Buech iber den neügen Hochaltar In Der Kierchen S. AEGidij Soc[ie]t[at]is Jesu Allhier In Grätz, so Angefangen Anno 1730: Mannath Augustij 1733. Den dito, bezalln den Herrn Ignatij florer vor das Hochaltar Bladt Acortierter Masßen 400 fl. Item vor die Zweij Seüdten gemäl an der Kirchen Mauer Acortierter masßen $100 \mathrm{fl}$. Verkürzt wiedergegeben in KRAUS-MÜLLER 1982 (Anm. 65), S. 26. Siehe dazu KRAUSMÜLLER 1981 (Anm. 65), 2, S. 8-9, Ö 9-Ö 11, und KRAUS-MÜLLER 1982 (Anm. 65), S. 62, Kat. Nr. 9 und 10.

68 StLA, Graz-Stadt, K. 137, H. 792, Hand Buech iber den neügen Hochaltar In Der Kierchen S. AEGidij Soc[ie] t[at]is Jesu Allhier In Grätz, so Angefangen Anno 1730: Mannath May a[nn]o 1730. Dem Herrn Ignaz flor vor die Delination $\mathrm{Zu}$ dem Hochaltar bezalt $24 \mathrm{fl}$. Mit leichten Abweichungen zitiert bei KRAUS-MÜLLER 1981 (Anm. 65), 2, S. 116, E 81. Siehe dazu KRAUS-MÜLLER 1981 (Anm. 65), 1, S. 196, Anm. 108, und 2, S. 8, Ö 9, sowie KRAUS-MÜLLER 1982 (Anm. 65), S. 26. 


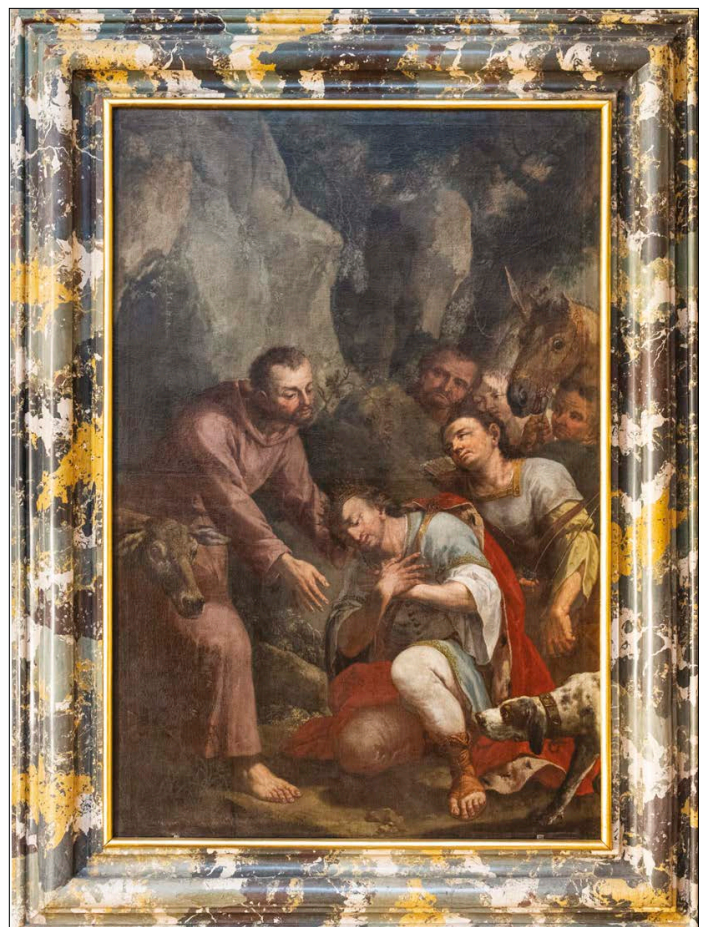

17. Franz Ignaz Flurer: Der hl. Ägidius und der Westgotenkönig Wamba, 1733, Dom, Graz

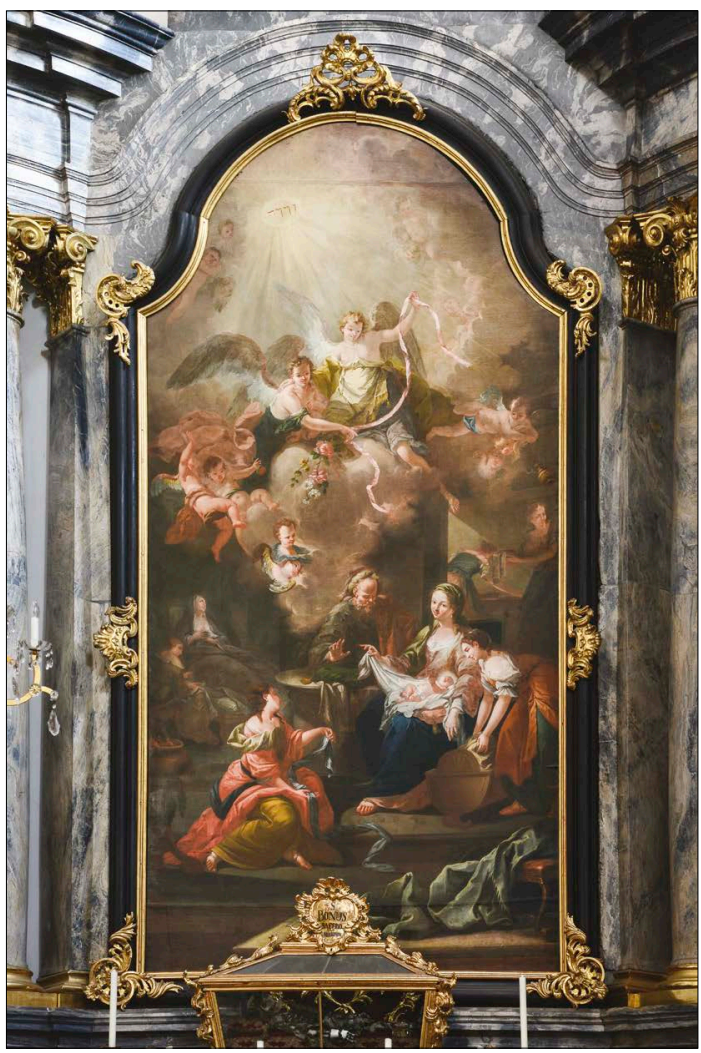

19. Lukas de Schram: Die Geburt der Maria, 1745, Wallfahrtskirche Mariatrost, Graz

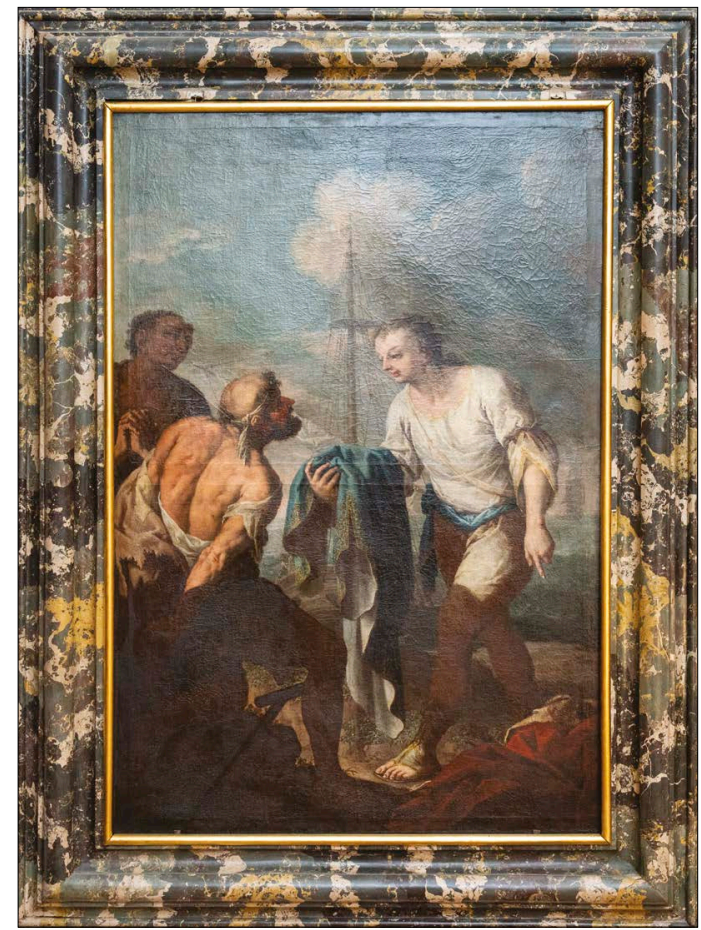

18. Franz Ignaz Flurer: Der hl. Ägidius reicht einem Armen sein Gewand, 1733, Dom, Graz

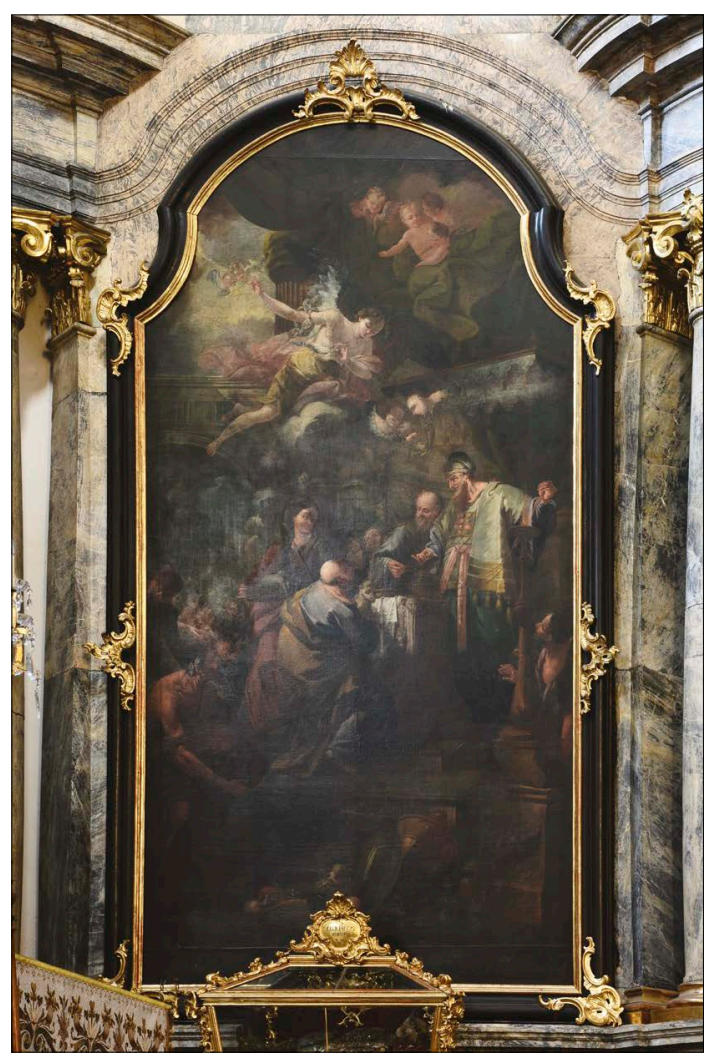

20. Lukas de Schram: Der hl. Joachim im Tempel, 1745, Wallfahrtskirche Mariatrost, Graz 
Weitere Belege für die Kosten von Altarbildern in der Steiermark sind im Zusammenhang mit den beiden von Lukas de Schram (1702-1765) geschaffenen Gemälden in der Wallfahrtskirche Mariatrost in Graz überliefert. Am 15. November 1736 schloss der Maler einen Vertrag mit Provinzial Ferdinand Stöger über die beiden großen Gemälde über den Altären der beiden Querhausarme ab. Als Lohn für die Altarbilder mit der Geburt der Maria (Abb. 19) und dem Hl. Joachim im Tempel (Abb. 20) sollte der Maler 500 Gulden erhalten. ${ }^{69}$ Die beiden Altarbilder wurden nach ihrer Fertigstellung aus Wiener Neustadt und Wien nach Graz geschickt. ${ }^{70}$

Die von Lukas de Schram begonnene Ausmalung der Wallfahrtskirche Mariatrost wurde von Johann Baptist Scheit (gest. 1755) zu Ende geführt. Bereits 1743 hatte Scheit für das Altarbild mit der Fürbitte des hl. Jakobus bei der Gottesmutter für die Pfarre Kaindorf (Abb. 21), das für den ehemaligen Hochaltar der Pfarrkirche St. Jakobus in Kaindorf bestimmt war, 44 Gulden erhalten. ${ }^{71}$ Die für das Hochaltarbild gezahlte Summe ist im Vergleich zu den Beträgen, die für Gemälde von Franz Carl Remp, Hans Adam Weissenkircher oder Johann Veit Hauckh aufgewendet werden mussten, vergleichsweise gering. Der äußerst niedrige Preis kann vielleicht damit begründet werden, dass die Gemeinde Kaindorf in den ersten vier Jahrzehnten des 18. Jahrhunderts von zahlreichen Katastrophen heimgesucht wurde ${ }^{72}$ die zu einer angespannten wirtschaftlichen Lage führten, in der es nicht möglich war, mehr als 44 Gulden für das neue Altarbild aufzubringen. Denkbar wäre auch in diesem Fall ein ganz grundsätzlich niedrigeres Preisniveau bei Gemälden, die nicht für Graz, sondern das Umland bestimmt waren.

69 Vertrag vom 1736, 15. November, zitiert nach KOHLBACH s. a. (Anm. 32), S. 209: Vertrag: Primo verobligire ich Lucas von Schram vor die 2 grossen Seitenaltär, zu welchen ich die Baurisse alss Benefactor gemacht, 2 gehörige Altar Blötter mit 18 Schuh hoch vnd 9 Schuh breit in Oel zu mahlen nach folgenden Concept: an einem Altar die Geburth Marien mit der h. Anna, an andern den hl. Joachim, wie er Gott anrueffet vmb einen Nachfolger zu gekhomen, vor welche 2 grosse Altarblätter Pater Provinzial a die der Liefferung mir zu bezahlen 500 fl. sich verbindet. Ähnlich bei ZAHN 1899 (Anm. 36), S. 292. Der Vertrag sollte sich im StLA, Finanzlandesdirektion, Nr. 3552-3591 (Mariatrost) befinden, ist dort aber nicht auffindbar. Siehe dazu KOHLBACH 1951 (Anm. 23), S. 199-200, und Erika MAURITSCH, Die Fresken des Lucas de Schram und des Johann Babtist [sic!] Scheit in der Mariatroster Kirche bei Graz. Eine ikonographischstilgeschichtliche Untersuchung, Graz 1995 (ungedruckte Diplomarbeit), S. 90, Qu 13. Nach Mauritsch soll sich dieses Dokument im DAG, Faszikel Maria-Trost, Kirchensachen befinden, aber es ist auch dort nicht auffindbar.

70 Am 4. Februar 1738 schreibt der Maler aus Ödenburg, er habe sich in Wien und Wienerneustadt mit Paulinern getroffen und mache mit hiesigen Herrn gewesten Burgermeister demnächst eine „Kirchfahrt nachher Maria Trost“. Siehe dazu KOHLBACH s. a. (Anm. 32), S. 209-210. Kohlbach datiert das Schreiben auf den 4. Februar, ohne das Jahr anzugeben, aber aus dem Zusammenhang wird ersichtlich, dass das Jahr 1738 gemeint sein muss. MAURITSCH 1995 (Anm. 69), S. 90-91, QU 15, die davon ausgeht, dass die Gemälde 1745 fertiggestellt waren, datiert den Brief auf den 4. Februar 1749. Auch dieser Brief, der sich laut Mauritsch im DAG, Faszikel Maria-Trost, Kirchensachen befinden soll, ist dort nicht auffindbar. Möglicherweise wurden die beiden Altarbilder jedoch erst 1749 oder 1750 fertiggestellt, denn Lukas de Schram bestätigte am 17. Oktober 1750 aus Ödenburg, 300 Gulden für die beiden Altarbilder erhalten zu haben (KOHLBACH s. a. (Anm. 32), S. 213). Das Schreiben, das Mauritsch nicht erwähnt, ist in den Grazer Archiven nicht auffindbar. Da für die beiden Altarbilder ein Gesamtpreis von 500 Gulden vereinbart worden war, kann dies nur die abschließende Zahlung an den Maler gewesen sein. Die restlichen 200 Gulden waren ihm wahrscheinlich bereits 1738 als Anzahlung ausgehändigt worden, denn ein Betrag in dieser Höhe wird in einem Schreiben des Malers Lukas de Schram an den Prior, das Kohlbach in das Jahr 1738 datiert, eingefordert und angewiesen (KOHLBACH s. a. (Anm. 32), S. 209). Die beiden Altarbilder wurden in diesem Schreiben aber offenbar nicht erwähnt. Auch dieses Dokument ist in den Grazer Archiven nicht auffindbar.

71 Zitiert nach KOHLBACH s. a. (Anm. 32), S. 612: 1743 Die Kirche für das Hochaltarblatt 44 fl. Siehe dazu MAURITSCH 1995 (Anm. 69), S. 15, mit Verweis auf Guido SCHOBER, Das Hochaltarbild in der Pfarrkirche, Pfarrbrief der Pfarre Kaindorf, April 1967, s. p. Schober führt als Quelle die Pfarrchronik Kaindorf an.

72 SCHOBER 1967 (Anm. 71) nennt die Zerstörungen und Verwüstungen durch Kuruzzeneinfälle in den Jahren 1704 bis 1708, die Kältejahre 1709 und 1740, Viehseuchen in den Jahren 1710 bis 1712 sowie 1724 bis 1729 in Kaindorf und der gesamten Steiermark, die Pest im Jahre 1713 und Dauerregen sowie Überschwemmungen im Sommer 1716, von denen in der Kaindorfer Pfarrchronik berichtet wird. 


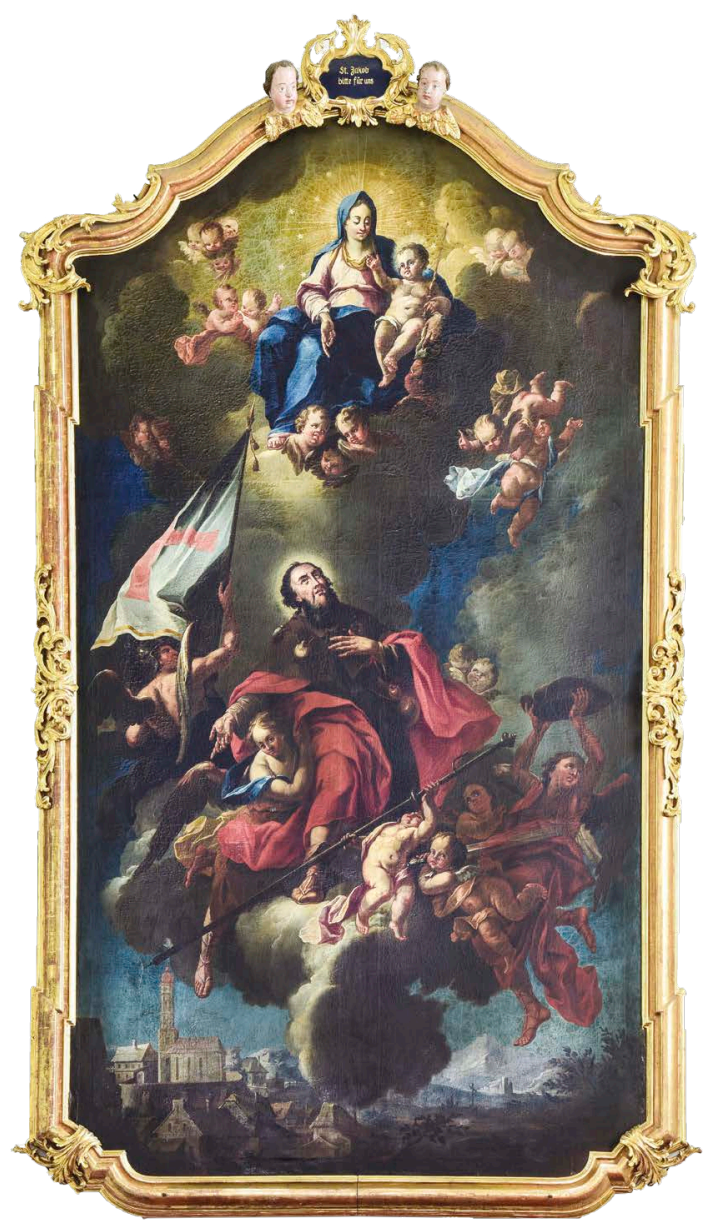

21. Johann Baptist Scheit: Fürbitte des hl. Jakobus bei der Gottesmutter für die Pfarre Kaindorf, 1743, Pfarrkirche St. Jakobus, Kaindorf

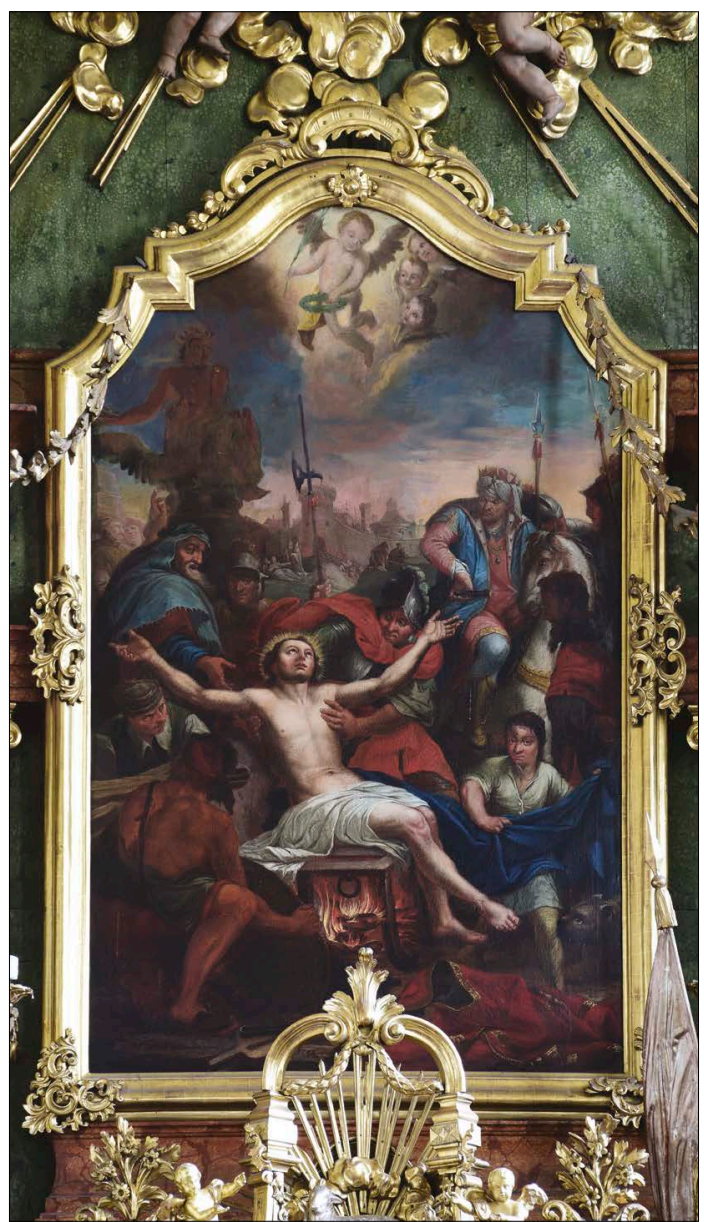

22. Johann Baptist Scheit: Das Martyrium des hl. Laurentius, 1748, Pfarrkirche St. Laurentius, St. Lorenzen im Mürztal

In der zweiten Hälfte des Jahres 1748 arbeitete Scheit in St. Lorenzen im Mürztal, wo er zwei Gemälde für den barocken Hochaltar der Pfarrkirche schuf, die mit insgesamt 190 Gulden vergütet wurden. ${ }^{73}$ Das signierte und datierte Hauptbild zeigt Das Martyrium des hl. Laurentius (Abb. 22), das zweite Bild, bei dem es sich möglicherweise um das kleinere Oberbild des Altars handelte, ist nicht mehr nachweisbar. Aus dem Gesamtbetrag kann erschlossen werden, dass der Maler für das größere Hochaltarbild mehr als 100 Gulden erhielt.

Die 400 Gulden, die für Weissenkirchers Altarbild mit den Vierzehn Nothelfern (Abb. 9) sowie für das von Flurer geschaffene Hochaltarbild im Dom zu Graz (Abb. 16) und die 350 Gulden, die für Hauckhs ehemaliges Hochaltarbild mit der Himmelfahrt Mariä (Abb. 11) in der Franziskanerkirche gezahlt wurden, sind die höchsten Summen, die für sehr große Altarbilder in der Steiermark gezahlt

73 MAURITSCH 1995 (Anm. 69), S. 15 mit Verweis auf Otto FRAYDENEGG-MONZELLO, Der Hochaltar zum hl. Laurentius, Nachrichten für die Freunde der Pfarrkirche von St. Lorenzen im Mürztal, Nr. 13, Juni 1994, S. 4-11, besonders S. 5. Zum Hochaltar siehe Otto FRAYDENEGG-MONZELLO, Hauptpfarrkirche St. Lorenzen im Mürztal, Salzburg 1994 (Christliche Kunststätten Österreichs, 258), S. 8-11. Das Altarbild ist mit Rahmen $170 \mathrm{~cm}$ hoch. 
wurden. Immer noch teuer, aber mit je 300 Gulden dennoch wesentlich günstiger zu bekommen, waren die beiden Altargemälde (Abb. 1 und 2), die Franz Carl Remp für die Stiftskirche in Kremsmünster geschaffen hatte. Die Preise für mittelgroße Altarbilder variierten zwischen 50 Gulden, die für ein jedes der beiden von Franz Ignaz Flurer geschaffenen Seitenbilder im Chor des Grazer Doms (Abb. 17 und 18) gezahlt wurden, und 200 Gulden für Hans Adam Weissenkirchers Altarbild in Seewiesen (Abb. 8), wobei die von Johann Veit Hauckh geschaffenen Altarbilder in St. Andrä im Sausal (Abb. 12 und 13), in der Grazer Dreifaltigkeitskirche (Abb. 10) und in der Stiftskirche in Rein (Abb. 14) zu den Werken der mittleren Preisklasse gehörten.

Die Bezahlung der in der Steiermark tätigen Maler wurde jedoch vom Verdienst italienischer Künstler oder des in Venedig tätigen Malers Johann Carl Loth übertroffen. ${ }^{74}$ Das mittelgroße Altarbild mit der hl. Katharina und das kleinere Brustbild der hl. Barbara im Kloster Tegernsee wurden um 1690 von Loth geschaffen und kosteten zusammen 400 Gulden. ${ }^{75}$ Für das größere Altarbild mit Christus am Kreuz und den Heiligen Maria, Johannes und Maria Magdalena erhielt Loth 500 Gulden, ${ }^{76}$ für die noch größeren Altarbilder mit der Verleihung des Rosenkranzes an den hl. Dominikus und das Schutzengelbild sogar jeweils 600 Gulden. ${ }^{77}$

Ähnlich gut bezahlt wurde wohl auch der zu dieser Zeit in Wien tätige Antonio Bellucci, der das großformatige Gemälde der Maria Immaculata mit Adam und Eva (Abb. 23) über dem Seitenaltar der Grazer Katharinenkirche schuf. ${ }^{78}$ Gemäß einer Specification vom 5. Mai 1699 erhielt Bellucci eine Abschlagszahlung in Höhe von 300 Gulden. ${ }^{79}$ Eigenmächtig hatte der Maler in Augsburg eine hochwertige Leinwand bestellt, deren Kosten in der Specification und anderen Dokumenten mit

74 In einer Aufstellung der Kosten für Gemälde, die Johann Carl Loth am 22. Februar 1692 an Bernhard Wenzl, den Abt von Tegernsee, schickte, heißt es: Spezification / Erstlich ist S. Catharina plath zu sambt dem prustpilt der heiligen Barbara bezahlt worden mit 100 specie dugaten id est $400 \mathrm{fl}$. / Christus am creiz mit sambt der Grablegung umb $500 \mathrm{fl}$. / .. / Das Rosenkhranz pilt, und der Schuczengl sein bezahlt wordten als iedes per $600 \mathrm{fl}$. zusammen aber mit 1200 fl. (München, Kreisarchiv, K.L.Fasc. 875/520, zitiert nach Gerhard EWALD, Johann Carl Loth, Amsterdam 1965, S. 42). Diese Rechnung wird, jedoch ohne Erwähnung der von Loth ebenfalls angeführten Kreuzigung Christi, zitiert bei RUCK 1982 (Anm. 20), S. 24, Anm. 47, die irrtümlich annimmt, dass ein Gemälde von Loth 400 Gulden kostete. Laut Vertrag sind es aber zwei Gemälde der hll. Katharina und Barbara. Siehe dazu EWALD 1965 (Anm. 74), S. 38-39, Exkurs 3.

75 Zum Altarbild der hl. Katharina siehe EWALD 1965 (Anm. 74), S. 95-96, Kat. Nr. 318. Das Gemälde hat die Maße 224 x 130 cm. Zum Brustbild der hl. Barbara siehe EWALD 1965 (Anm. 74), S. 86, Kat. Nr. 253. Das Gemälde misst $97 \times 87 \mathrm{~cm}$.

76 Zur Kreuzigung Christi siehe EWALD 1965 (Anm. 74), S. 80, Kat. Nr. 202. Das wohl beschnittene Gemälde hat die Maße von ca. 270 x $165 \mathrm{~cm}$. Es befindet sich heute in der Pfarr- und Wallfahrtskirche Christkindl bei Steyr in Oberösterreich.

77 Zum Rosenkranzbild siehe EWALD 1965 (Anm. 74), S. 87, Kat. Nr. 256. Das Gemälde misst 295 x 195 cm. Zum Schutzengelbild siehe EWALD 1965 (Anm. 74), S. 98, Kat. Nr. 338. Das Gemälde misst 296 x 195 cm. Beide Gemälde befinden sich in den Bayerischen Staatsgemäldesammlungen.

78 Die im Zusammenhang mit dem Seitenaltar in der Grazer Katharinenkirche erhaltenen Akten befinden sich im StLA, Hofkammer, HK 1699-II-15, 16. Der in Wien tätige Maler Antonio Bellucci wird in einem Dokument vom 5. Februar erstmals erwähnt. Das Altarbild hat die Maße 450 x $280 \mathrm{~cm}$. Fabrizio MAGANI, Antonio Bellucci. Catalogo ragionato, Rimini 1995, S. 132.

79 StLA, Hofkammer, HK 1699-II-15, 16, Specification. / Waß von denen jüngst unter däto 13. Februar: 1699. zu hanferttigung deß Neuen Saithen altar in dem kay[ser]l:[ichen] Mausolaeo alhier angeschafften 1000 fl. Bezalt worden /.../ Erstlichen den Wiennerischen Maller, wegen hanferttigung des altar Blatts à Conto bezalt - $300 \mathrm{fl}$. / Dan wegen Lainbath - $60 \mathrm{fl}$. Siehe dazu Josef WASTLER, Das Mausoleum Ferdinand II. in Grätz, Mittheilungen der k. k. Central-Commission, n. F. 10, 1884, S. 7; KOHLBACH 1951 (Anm. 23), S. 100-101, und KOHLBACH s. a. (Anm. 32), S. 77 mit dem Datum vom 5. Mai 1699. 
60 Gulden angeführt sind ${ }^{80}$ Wann Belluccis Gemälde nach Graz geliefert wurde und auf welche Summe sich die gesamten Kosten für das Gemälde beliefen, geht aus den Dokumenten nicht hervor. ${ }^{81}$ Gesichert ist nur, dass das Altarbild bei der Weihe der Katharinenkirche und des Mausoleums am 28. August 1714 fertiggestellt war. ${ }^{82}$ Auch wenn nicht bekannt ist, wieviel Antonio Bellucci insgesamt für das Altarbild in der Katharinenkirche erhielt, kann man aus der Aconto-Zahlung in Höhe von 300 Gulden schließen, dass der gesamte Lohn wesentlich höher gewesen sein muss. Ob Bellucci 600 oder 800 Gulden erhielt, kann nur vermutet, aber nicht bewiesen werden. Einen Vergleichswert bietet das von Antonio Bellucci in den Jahren 1701 bis 1704 geschaffene hochovale Gemälde mit der Himmelfahrt Mariä am Hochaltar der Stiftskirche in Vorau (Abb. 24), für das der Künstler 500 Gulden erhielt. ${ }^{83}$

Die genannten und miteinander verglichenen Geldbeträge vermitteln einen Eindruck von den Kosten, die für die Anschaffung von Altar-

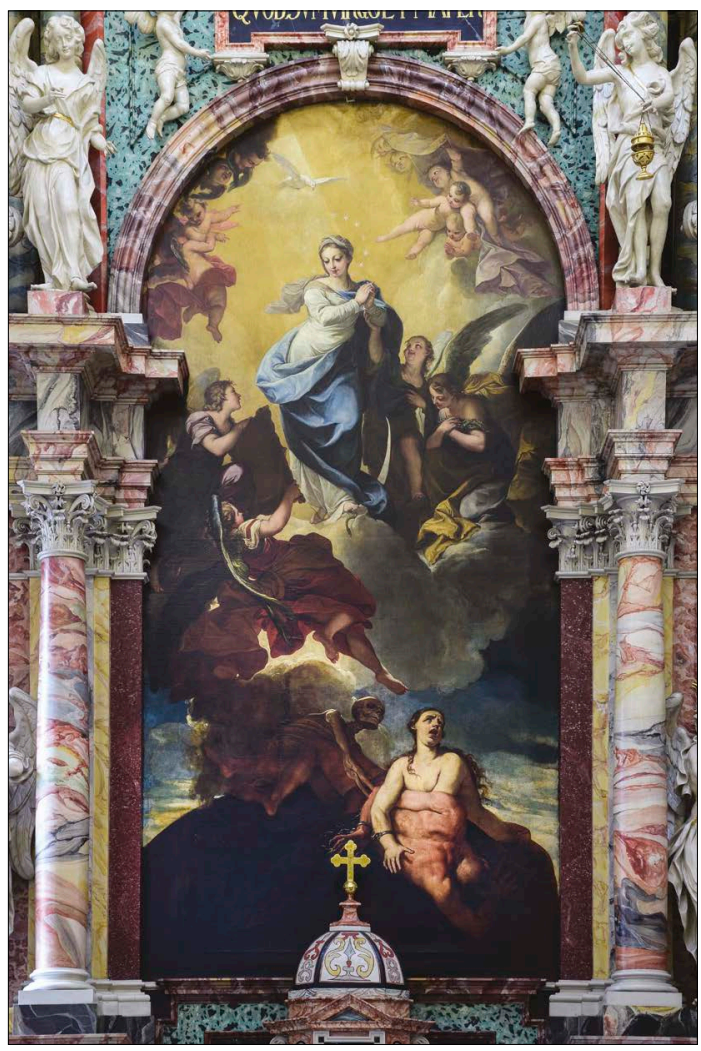

23. Antonio Bellucci: Maria Immaculata mit Adam und Eva, nach 1699, Katharinenkirche, Graz bildern und anderen Gemälden aufgewendet werden mussten. Ganz allgemein kann festgestellt werden, dass die Werke der in der Steiermark, Innerösterreich und den benachbarten habsburgischen Landen tätigen Künstler durchaus unterschiedlich vergütet wurden. Dies kann unter anderem mit der Größe der Gemälde, der Anzahl der dargestellten Personen, der Stellung der Auftraggeber und dem Ansehen der ausführenden Künstler erklärt werden, ist aber wohl auch auf die Unterschiede zwischen der Landeshauptstadt oder anderen Zentren und kleineren Städten oder Pfarreien im Umland zurückzuführen. Auch müssen der Rang und die Bedeutung der Auftraggeber berücksichtigt werden. Demzufolge wurde ein vom

80 Siehe dazu Anm. 79.

81 WASTLER 1884 (Anm. 79), S. 7, erwähnt nur die Anzahlung in Höhe von 300 Gulden. KOHLBACH 1951 (Anm. 23), S. 100-101, behauptet, dass Bellucci insgesamt 800 Gulden für das Gemälde erhalten haben soll, bleibt aber den Nachweis schuldig. Auch bei KOHLBACH s. a. (Anm. 32) findet sich kein Beleg für eine weitere Zahlung oder eine Abschlusszahlung an Bellucci. In den Expedita zu Hofkammersachen der Jahre 1699 bis 1714 (StLA, IÖ, HK 1699-1714, HK-Rep., 1699-1714) findet sich ebenfalls keine weitere Zahlung an Bellucci oder im Zusammenhang mit dem Seitenaltar.

82 WASTLER 1884 (Anm. 79), S. 7, und KOHLBACH 1951 (Anm. 23), S. 104. KOHLBACH s. a. (Anm. 32), S. 79, nennt den 28. Juli 1714 als Weihedatum. MAGANI 1995 (Anm. 78), S. 132, datiert das Gemälde um 1701.

83 Ottokar KERNSTOCK, Das Protocollum Voraviense antiquissimum, Beiträge zur Kunde steiermärkischer Geschichtsquellen, 22, 1887, S. 41: /.../ das Altarbild malte der Venetianer Antonio Pelluzzi für $500 \mathrm{fl}$.... - Notizen von Propst Leisls Hand. Zum Hochaltar siehe Bernhard MAYRHOFER, Stift Vorau. Die Bau- und Ausstattungsgeschichte, Passau 2017, S. 124-126. Das hochovale Gemälde misst in der Höhe und Breite 320 x 210 cm. MAGANI 1995 (Anm. 78), S. 132, datiert das Gemälde 1702-1703. 


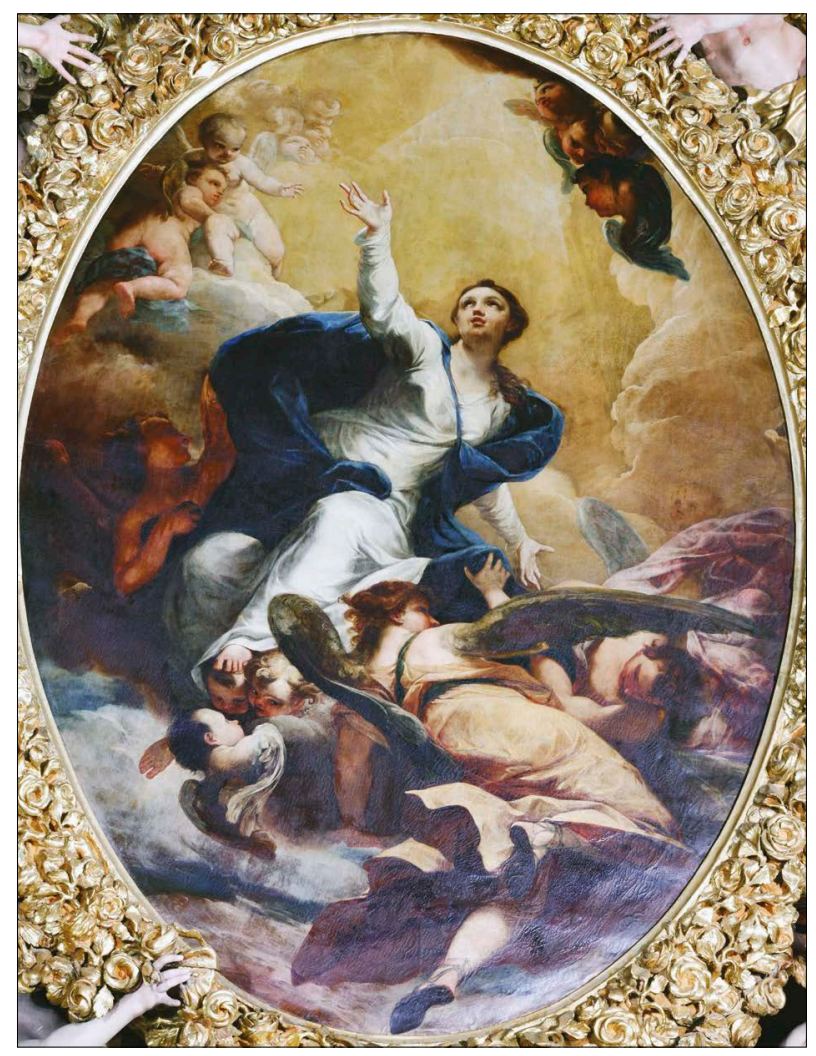

24. Antonio Bellucci: Himmelfahrt Mariä, 1701-1704, Stiftskirche, Augustiner-Chorherrenstift Vorau
Abt des Stifts Kremsmünster bestelltes Gemälde sehr wahrscheinlich besser bezahlt als ein vergleichbares für Stift Rein bestelltes Altarbild. Außergewöhnlich hoch sind die Preise, die für Werke des in Venedig tätigen Carl Loth oder des in Wien tätigen Venezianers Antonio Bellucci gezahlt werden mussten. Auch wenn sich für die von Franz Carl Remp in Innerösterreich geschaffenen Gemälde keine Zahlungsbelege erhalten haben, kann vermutet werden, dass er nach Wien ging, weil dort zahlungskräftigere Auftraggeber und ein insgesamt lukrativerer Markt zu finden waren. Inwieweit auch wirtschaftlich gute oder schlechte Zeiten Einfluss auf die Gestaltung der Preise hatten, kann aufgrund der geringen Menge vergleichbarer Wertangaben nicht ermittelt werden.

Der Wert des Geldes, das für ein Altarbild oder ein Porträt aufgebracht werden musste, kann anhand der Preise, die in bestimmten Jahren für Lebensmittel, Löhne und Dinge des täglichen Gebrauchs gezahlt wurden, besser be-

stimmt werden. ${ }^{84}$ Dass Antonio Bellucci 1699 eigenmächtig in Augsburg für insgesamt 60 Gulden qualitativ hochwertige Leinwand bestellte, um darauf die Immaculata für den Hochaltar in der Grazer Katharinenkirche zu malen, ist in den Akten der Hofkammer dokumentiert. ${ }^{85}$ Leinwand war allerdings auch weitaus günstiger zu bekommen, denn die acht Ellen, die 1731 für die drei von Franz Ignaz Flurer zu malenden Altarbilder im Chor des Grazer Doms geliefert worden waren, wurden im Mai 1731 mit 24 Gulden bezahlt. ${ }^{86}$

Einen Richtwert für die Kaufkraft des Geldes in der ersten Hälfte des 18. Jahrhunderts gibt das Protokoll eines Hauskaufs in Hartberg durch den Maler Johann Cyriak Hackhofer. Am 7. Juni 1728 erwarb der Maler das Haus am Rindermarkt von Maria Eleonora Mayr, der Witwe des Malers Franz

84 PRIBRAM 1938 (Anm. 33). Die von Pribram veröffentlichten Preise und Löhne wurden hauptsächlich in Wien und Niederösterreich ermittelt. Zu Steiermark und Graz siehe Franz MENSI, Zur Geschichte der Preise und Löhne in Steiermark, Zeitschrift des historischen Vereines für Steiermark, 29, 1935, S. 103-106, und Fritz POPELKA, Die Lebensmittelpreise und Löhne in Graz vom 16. bis zum 18. Jahrhundert, Vierteljahrschrift für Sozial- und Wirtschaftsgeschichte, 23, 1930, S. 157-218.

85 Siehe dazu Anm. 79.

86 StLA, Graz-Stadt, K. 137, H. 792, Hand Buech iber den neügen Hochaltar In Der Kierchen S. AEGidij Soc[ie] $\mathrm{t}$ [at]is Jesu Allhier In Grätz, so Angefangen Anno 1730: Mannath Maij anno 1731. Vor 8 Ellen Leinwandt Zu Dem Hochaltar Bladt à $3 \mathrm{fl}$. - $24 \mathrm{fl}$. Die Kosten für die Leinwand werden bei KRAUS-MÜLLER 1981 (Anm. 65) nicht erwähnt. 
Josef Mayr, für 200 Gulden und sechs Speciestaler, also insgesamt 212 Gulden. ${ }^{87}$ Etwa fünf Jahre später, am 8. April 1733, erwarb Franz Ignaz Flurer ein Haus am Mühlgang in Graz und einen Garten für 800 Gulden und 90 Gulden Leihkauf. ${ }^{88}$ Haus und Garten wurden nach dem Tod von Flurers Gattin im Jahre 1753 bereits auf 1400 Gulden geschätzt und sollten für 1500 Gulden verkauft werden. ${ }^{89}$ Dass Flurer 600 Gulden mehr für das südlich der Mur gelegene Haus mit Garten in Graz bezahlen musste als Hackhofer für sein Haus in Hartberg, kann wohl nicht allein darauf zurückgeführt werden, dass das Haus in der Landeshauptstadt größer als das in der Oststeiermark war, sondern ist wahrscheinlich auch den höheren Grundstückspreisen in Graz geschuldet. Das Geld für den Kauf des Hauses in Graz war jedenfalls gut angelegt, denn der Wiederverkaufswert lag bei geschätzten 1400 Gulden, was einer Wertsteigerung von 75 Prozent in einem Zeitraum von 20 Jahren entspricht.

87 StLA, Stadtgericht Hartberg, Stadtgerichtsprotokoll, 7. Juni 1728: Den 7. Juny 1728: in beysein H: Mathias Perschl Stattrichter, H: Joh. Michael Paltauff, H: Mathias Reiff, und H: Ferdinandt Walnefer, verkhaufft Maria Eleonora Maijrin Wittib Ihr bürgerl: Behaußung auf den Rinnenmarkht, dem H. Johann Cyriacus Hakhoffer Mallern v: Vorrau pr. 200 fl: und 6 Species Thaller Leykhauff, die 6 Species Thaller leykhauff und 50 fl: $v$ : Khauffschilling seint in gerichts Hauß gleich Erlegt worden, die übrige $150 \mathrm{fl}$ : aber Versprückt H. Hackhoffer inner 4 Wo[c]hen zu Erlegen, und die Fr: Wittib ein halbes Jahrlang in Hauß zu behalten, so hat auf dißes sie Fr: Mayrin das hauß bei Gericht aufgegeben, und Er H: Hakhoffer solliches der ordnung nach bestandten. Geringfügig anders bei WEEBER 1987 (Anm. 56), S. 278, Qu 20. Siehe dazu SIMMLER 1914 (Anm. 63), S. 657. Ein Speciestaler entsprach 120 Kreuzern, also 2 Gulden. Siehe dazu PRIBRAM 1938 (Anm. 33), S. 43.

88 StLA, GB I, Nr. 4726, Fol. 105r: Den 8. April 1733 Verkhauffen unternamben Ihro Excellenz der Hochwolgebornen Fr:[au] Fr:[au] Maria Anna von Steitz einer geborenen v:[on] Mosßhardt Wittib als gerhabin ihr der Zeit Ingehabten so genannten Strugglischen Gartten und Haus ausser daß Müllgang und der fürstl:[ichen] Herrschafft Eggenberg dienstbar des H:[errn] Förner, I:[nner] Ö:[sterreichischer] D:[okto]r Verordneten Curatoren dem H:[errn] Franz Ignatij Flurer Mallern in Gräz per $800 \mathrm{fl}$. KauffSuma und $90 \mathrm{fl}$. Leijkhauf betragt detto 10 Pfennig. Leicht gekürzt bei KRAUS-MÜLLER 1981 (Anm. 65), 1, S. 7. Ebenso in KRAUS-MÜLLER 1982 (Anm. 65), S. 32. Zum Leihkauf, mit dem ein Umtrunk oder Fest zur Besiegelung des Vertragsabschlusses, aber auch eine Anzahlung oder ein Aufgeld gemeint sein kann, siehe Johann Christoph ADELUNG, Grammatisch-kritisches Wörterbuch der Hochdeutschen Mundart, 2, Leipzig 1796, Sp. 2013.

89 Flurers unmündiger Sohn, Franz Xaver, der nach dem Tod seiner Mutter Anna Maria Crischan im Jahr 1753 als Mündel unter der Vormundschaft seines Großvaters Leopold Lux stand, erbte das Haus am Mühlgang, das 1754 auf 1400 Gulden geschätzt wurde und für 1500 Gulden an Rosalia Trollin verkauft werden sollte. Verschiedene ähnlich formulierte Schreiben im StLA, WSTA, Nr. 25, Akt 284. Darin das Schreiben des Leopold Lux an die Hofkommission vom 10. May 1745: /.../ daß es in der Schatzung zu $1400 \mathrm{fl}$. /.../ hingegen soliches um $1500 \mathrm{fl}$. /.../ verkauffet werden möge. KRAUS-MÜLLER 1981 (Anm. 65), 1, S. 189 und 191, geht davon aus, dass das Haus bereits am 4. April 1754 für 1500 Gulden verkauft wurde. Siehe dazu KRAUS-MÜLLER 1982 (Anm. 65), S. 44-45. 


\section{Bibliographie}

ADELUNG, Johann Christoph, Grammatisch-kritisches Wörterbuch der Hochdeutschen Mundart, 2, Leipzig 1796.

ALVIŽ, Josipa, Slikarstvo XVII. i XVIII. stoljeća u kapucinskim crkvama i samostanima u Hrvatskoj/ Painting of the $17^{\text {th }}$ and $18^{\text {th }}$ Century in the Capuchin Churches and Monasteries in Croatia, 1-2, Zagreb 2015 (ungedruckte Dissertation).

Archivalische Vorarbeiten zur Österreichischen Kunsttopographie. Gerichtsbezirk und Stift Kremsmünster, 1-2 (Hrsg. Willibrord Neumüller), Wien 1961.

The Art Market in Italy, 15th-17th Centuries/Il mercato dellarte in Italia, secc. XV-XVII (Hrsg. Marcello Fantoni, Louisa C. Matthew, Sara F. Matthews-Grieco), Modena 2003.

Der Barockmaler Franz Carl Remp 1674-1718, Österreichische Galerie, Wien und Joanneum, Graz, Wien 1974.

BECK, Marina, II.36 Graz, Statuta Pictorum. Kommentierte Edition der Maler(zunft)ordnungen im deutschsprachigen Raum des Alten Reiches. 2: Esslingen bis Konstanz (Hrsg. Andreas Tacke), Petersberg 2018, S. 250-276.

BRAUN, Joseph, Die liturgischen Paramente in Gegenwart und Vergangenheit. Ein Handbuch der Paramentik, Freiburg $1924^{2}$.

EMMINGHAUS, Johannes H., Fastentuch, Reallexikon zur Deutschen Kunstgeschichte, 7, München 1979, Sp. 826-848.

EWALD, Gerhard, Johann Carl Loth, Amsterdam 1965.

FRAYDENEGG-MONZELLO, Otto, Der Hochaltar zum hl. Laurentius, Nachrichten für die Freunde der Pfarrkirche von St. Lorenzen im Mürztal, Nr. 13, Juni 1994, S. 4-11.

FRAYDENEGG-MONZELLO, Otto, Hauptpfarrkirche St. Lorenzen im Mürztal, Salzburg 1994 (Christliche Kunststätten Österreichs, 258).

HOCHHUBER, Karl, Pfarrkirchen bei Bad Hall, Oberösterreich, Salzburg 1962 (Christliche Kunststätten Österreichs, 24).

HUTZ, Ferdinand, Der Hochaltar von Mönichwald und seine Künstler, Blätter für Heimatkunde, 69, 1985, S. 83-86.

KERNSTOCK, Ottokar, Das Protocollum Voraviense antiquissimum, Beiträge zur Kunde steiermärkischer Geschichtsquellen, 22, 1887, S. 35-58.

KOHLBACH, Rochus, Die gotischen Kirchen von Graz, Graz 1950.

KOHLBACH, Rochus, Die barocken Kirchen von Graz, Graz 1951.

KOHLBACH, Rochus, Kirchen- und Schlösserrechnungen, s. a. (maschinenschriftlicher Nachlass), Bundesdenkmalamt, Abteilung für Steiermark, Inv. Nr. 3277.

KORTH, Thomas, Stift St. Florian. Die Entstehungsgeschichte der barocken Klosteranlage, Nürnberg 1975 (Erlanger Beiträge zur Sprach- und Kunstwissenschaft, 49).

KRAUS-MÜLLER, Ulrike, Franz Ignaz Flurer (1688-1742), 1-2, Graz 1981 (ungedruckte Dissertation).

KRAUS-MÜLLER, Ulrike, Franz Ignaz Flurer (1688-1742). Ein Barockmaler in der Steiermark (Hrsg. Wilhelm Steinböck), Stadtmuseum Graz, Graz 1982.

KUDIŠ, Nina, BOLIĆ, Marin, Value and Prices of Paintings in Venice, Istria and Dalmatia during the $17^{\text {th }}$ Century (Some Examples), Imaging the Image/Lik slike (Hrsg. Nataša Lah, Nenad Miščević, Miško Šuvaković), Rijeka 2019, S. 83-92.

Die Kunstdenkmäler des Benediktinerstiftes Kremsmünster, 1: Das Stift - Der Bau und seine Einrichtung (Bearb. Erika Doberer), Wien 1977 (Österreichische Kunsttopographie, 43).

Kunstmärkte zwischen Stadt und Hof. Prozesse der Preisbildung in der europäischen Vormoderne

(Hrsg. Andreas Tacke), Petersberg 2017. 
LECHNER, Georg Matthias, Der Barockmaler Franz Carl Remp (1675-1718), Wien 2010 (ungedruckte Dissertation).

Lexikon Capuccinum. Promptuarium historico-bibliographicum Ordinis Fratorum Minorum Capuccinorum (1525-1950), Rom 1951.

MAGANI, Fabrizio, Antonio Bellucci. Catalogo ragionato, Rimini 1995.

MAURITSCH, Erika, Die Fresken des Lucas de Schram und des Johann Babtist Scheit in der Mariatroster Kirche bei Graz. Eine ikonographisch-stilgeschichtliche Untersuchung, Graz 1995 (ungedruckte Diplomarbeit).

MAYRHOFER, Bernhard, Stift Vorau. Die Bau- und Ausstattungsgeschichte, Passau 2017.

MENSI, Franz, Zur Geschichte der Preise und Löhne in Steiermark, Zeitschrift des historischen Vereines für Steiermark, 29, 1935, S. 103-106.

Painting for Profit. The Economic Lives of Seventeenth-Century Italian Painters (Hrsg. Richard E. Spear, Philip L. Sohm), New Haven-London 2010.

POPELKA, Fritz, Die Lebensmittelpreise und Löhne in Graz vom 16. bis zum 18. Jahrhundert, Vierteljahrschrift für Sozial- und Wirtschaftsgeschichte, 23, 1930, S. 157-218.

PRIBRAM, Alfred Francis, Materialen zur Geschichte der Preise und Löhne in Österreich, 1, Wien 1938.

REDL, Victoria, Johann Veit Hauckh. Ein steirischer Barockmaler (1663-1746), Graz 1986 (ungedruckte Dissertation).

ROSENBERG-GUTMANN, Anny, Hans Adam Weissenkircher, Graz 1924 (ungedruckte Dissertation).

ROSENBERG-GUTMANN, Anny, Hanns Adam Weissenkirchner. Sein Leben und seine Kunst, WienGraz-Leipzig 1925 (Beiträge zur Kunstgeschichte Steiermarks und Kärntens, 2).

ROTH, Benno, Spätbarockes Kunstschaffen unter den Seckauer Dompröpsten, Seckau 1961 (Seckauer geschichtliche Studien, 16).

ROTH, Benno, Seckau. Der Dom im Gebirge. Kunsttopographie vom 12. bis zum 20. Jahrhundert, Graz-Wien-Köln 1984.

RUCK, Barbara, Hans Adam Weissenkircher, fürstlich Eggenbergischer Hofmaler (1646-1695). Mit einem Versuch zur Rekonstruktion des Programmes für seinen allegorischen Gemäldezyklus im Eggenberger Planetensaal, Graz 1982 (ungedruckte Dissertation).

RUCK, Barbara, Hans Adam Weissenkircher (1646-1695). Fürstlich Eggenbergischer Hofmaler (Hrsg. Friedrich Kryza-Gersch), Graz 1985.

SCHMITZ, Ida, Kirche und Kloster der Ursulinen in Graz. Ein Beitrag zur steiermärkischen Kunstgeschichte, Graz 1927 (ungedruckte Dissertation).

SCHOBER, Guido, Das Hochaltarbild in der Pfarrkirche, Pfarrbrief der Pfarre Kaindorf, April 1967, s. p.

SIMMLER, Johannes, Die Geschichte der Stadt, der Pfarre und des Bezirkes Hartberg, Hartberg 1914.

WASTLER, Josef, Steirisches Künstler-Lexicon, Graz 1883.

WASTLER, Josef, Das Mausoleum Ferdinand II. in Grätz, Mittheilungen der k. k. Central-Commission, n. F. 10, 1884, S. 1-10.

WASTLER, Josef, Die Ordnung der von Peter de Pomis gegründeten Maler-Confraternität in Graz, Beiträge zur Kunde steiermärkischer Geschichtsquellen, 23, 1891, S. 10-21.

WEEBER, Christine, Der Vorauer Stiftsmaler Johann Cyriak Hackhofer: 1675-1731, Graz 1987 (ungedruckte Dissertation).

WONISCH, Othmar, Ein Beitrag zur Weissenkircher-Forschung, Zeitschrift des historischen Vereines für Steiermark, 11, 1913, S. 358.

ZAHN, Joseph von, Steirische Miscellen. Zur Orts- und Culturgeschichte der Steiermark, Graz 1899. 


\section{Abbildungsnachweis}

1-4: Georg Lechner.

5-7: ๑ Wien, Bundesdenkmalamt, Fotoarchiv.

8-15, 19-23: Markus Enzinger.

16-18: Eva Kleinsasser.

24: Matej Klemenčič. 


\title{
Cena in vrednost slik okrog leta 1700 . O stroških za slike na Štajerskem
}

\author{
Povzetek
}

Pričujoči prispevek nudi pregled stroškov za oljne slike in predvsem oltarne podobe, ki so jih v času od konca osemdesetih let 17. stoletja do okrog leta 1750 morali plačati zlasti na Štajerskem za dela Frančiška Karla Remba in drugih slikarjev.

Za oltarni sliki velikega formata z upodobitvama Kristusa na križu in Smrti sv. Benedikta, ki ju je Frančišek Karel Remb leta 1712 naslikal za benediktinski samostan Kremsmünster v Gornji Avstriji, je slikar prejel po 300 goldinarjev. Naslednjega leta (1713) je Remb dobil za vsako od trinajstih slik nekoliko manjšega formata, ki so upodabljale legendo o ustanovitvi samostana in prizore iz življenja pomembnih benediktinskih svetnikov ter so bile nameščene na slope samostanske cerkve v Kremsmünstru, 200 goldinarjev, torej skupaj 2600 goldinarjev. Ob tem so v samostanu Kremsmünster Rembu konec maja 1713 plačali 100 goldinarjev za tri portrete cesarja Karla VI., od katerih je bil eden morda identičen s celopostavnim portretom cesarja v naravni velikosti, ki je zdaj v samostanskem depoju slik. Zaradi relativno nizke vsote za tri portrete smemo domnevati, da sta bili drugi dve sliki občutno manjšega formata in sta upodabljali cesarja v doprsnem izrezu. V gornjeavstrijskem samostanu St. Florian so Rembu februarja 1715 za tri supraporte z biblijskimi prizori (Samson in Dalila, Rebeka in Eliezer, Jobova preizkušnja) plačali 150 goldinarjev.

Že pred tem je bil podobno dobro plačan dvorni slikar knezov Eggenbergov, Hans Adam Weissenkircher. Za sliko velikega oltarja z upodobitvijo Sv. Lenarta za župnijsko cerkev v Seewiesnu na Štajerskem, ki je bila podrejena samostanu St. Lambrecht, je Weissenkircher leta 1688 prejel 200 goldinarjev. Štiristo goldinarjev naj bi bil slikar dobil leta 1692 za oltarno sliko Sv. Trojice, Marije, Jožefa in štirinajstih priprošnjikov $v$ sili za graško kapucinsko cerkev. Izjemno visoka vsota je bila verjetno posledica velikega formata oltarne slike in številnih figur, ki so na njej upodobljene. Vendar se zdi primerna, saj je Weissenkircher v prvih letih svoje službe dvornega slikarja Janeza Sajfrida kneza Eggenberga prejemal letno plačo 400 goldinarjev.

Leta 1702 so Weissenkircherjevemu učencu Johannu Veitu Hauckhu plačali 100 goldinarjev za sliko Sv. Trojice za veliki oltar v graški cerkvi Sv. Trojice. Deset let pozneje (1712) je dobil 60 goldinarjev za oltarno sliko, ki jo je Marija Rozalija, državna grofica Dietrichstein naročila za stransko kapelo v kapucinski cerkvi v Schwanbergu. Neobičajno visoko, a glede na velikost slike upravičeno je bilo plačilo, ki ga je Hauckh prejel leta 1719 za oltarno sliko Marijinega vnebovzetja, namenjeno za veliki oltar graške frančiškanske cerkve. Za oltarni sliki, ki ju je Hauckh v naslednjih letih naslikal za stranska oltarja v frančiškanski cerkvi, je slikar leta 1723 dobil skupaj 300 goldinarjev. V nasprotju s tem je Hauckh leta 1725 za oltarni sliki Sv. Urbana in Sv. Janeza Nepomuka za cerkev sv. Andreja v Sausalu prejel skupaj samo 150 goldinarjev. Nižjega plačila ne moremo razložiti samo z manjšim formatom oltarnih slik, temveč je bilo verjetno posledica različne ravni cen $\mathrm{v}$ deželni prestolnici in v njeni širši okolici. Srednje velika oltarna slika Sv. Ane Samotretje, sv. Jožefa in sv. Joahima za samostan Rein je bila leta 1731 plačana s 104 goldinarji.

Že leta 1715 je Hauckh prejel 150 goldinarjev za sliki oltarja Štirinajstih priprošnjikov v sili v graški cerkvi sv. Lenarta - verjetno za srednje veliko oltarno sliko in manjšo sliko v atiki. Tudi 1730 naj bi bilo slikarju izplačanih 150 goldinarjev za oltarno sliko s Štirinajstimi priprošnjiki v sili in sliko Sv. Donata v stranskih kapelah župnijske cerkve sv. Vida v Passailu.

Leta 1713 je notranjeavstrijska dvorna komora Johannu Veitu Hauckhu izplačala 75 goldinarjev za portret cesarja Karla VI. v dokolenskem izrezu in za dopasna portreta njegovih predhodnikov Leopolda 
I. in Jožefa I. Razmeroma nizko plačilo za portrete treh cesarjev lahko spet utemeljimo z dejstvom, da so bile slike namenjene kapucinskemu samostanu v Karlobagu ob skrajni meji Notranje Avstrije. Primernejše je bilo izplačilo 158 goldinarjev, ki jih je Hauckh od dvorne komore dobil leta 1723 za portret cesarja Karla VI., verjetno naslikan celopostavno in v naravni velikosti.

Vrednosti slik vorauskega samostanskega slikarja Johanna Cyriaka Hackhoferja v izbranem kontekstu ne moremo presojati, ker ni ohranjeno nobeno potrdilo o izplačilu za oltarne slike. Tri postne slike iz leta 1721, antependiji iz leta 1728 in druga manjša dela pa z oltarnimi slikami niso primerljivi.

Nepojasnjeno ostaja, zakaj je bilo Franzu Ignazu Flurerju leta 1733 za sliko Sv. Egidija in priprošnjikov za veliki oltar graške stolnice izplačanih 400 goldinarjev, medtem ko je za le nekoliko manjši sliki z upodobitvama iz življenja sv. Egidija, ki sta nameščeni na steni prezbiterija, prejel skupaj samo 100 goldinarjev.

S po 250 goldinarji sta bili primerno plačani veliki oltarni sliki $\mathrm{z}$ upodobitvama Marijinega rojstva in Sv. Joahima $v$ templju, ki ju je Lukas de Schram po letu 1736 naslikal za oltarja v prečni ladji romarske cerkve Mariatrost pri Gradcu.

Po drugi strani je slikar Johann Baptist Scheit za sliko Sv. Jakoba pred Marijo, ki jo je naslikal v začetku štiridesetih let 18. stoletja za veliki oltar župnijske cerkve v Kaindorfu, dobil samo 44 goldinarjev. To bi lahko pojasnili s slabim gospodarskim stanjem cerkvene občine $\mathrm{v}$ tem času ali pa tudi z oddaljenostjo kraja od graškega središča. Vendar je Scheit za oltarno sliko Mučeništva sv. Lovrenca in zdaj izgubljeno sliko v atiki baročnega velikega oltarja v župnijski cerkvi sv. Lovrenca v St. Lorenzen im Mürztal prejel skupaj 190 goldinarjev, kar se zdi povsem primerna vsota.

Visoke vsote, ki so jih izplačali za nekatere slike Hansa Adama Weissenkircherja, Franza Ignaza Flurerja ali Johanna Veita Hauckha, pa so močno presegla izplačila beneškim in v Benetkah delujočim slikarjem. Tako je nemški Benečan Johann Carl Loth prejel od samostana Tegernsee za veliko oltarno sliko Križanja s številnimi upodobljenimi figurami 500 goldinarjev. Za še večji oltarni sliki Sv. Dominik prejema rožni venec in Angel varuh in sv. Mihael je dobil po 600 goldinarjev. Na Dunaju delujočemu Antoniu Bellucciju so za veliko sliko Brezmadežne $z$ Adamom in Evo za stranski oltar v graški cerkvi sv. Katarine maja 1699 plačali 300 goldinarjev predujma. Čeprav ni znano, koliko je dobil v celoti, je moralo biti to plačilo večkratnik predujma. S 500 goldinarji je bila zelo dobro plačana tudi ovalna slika Marijinega vnebovzetja za veliki oltar samostanske cerkve v Vorauu, dokončana leta 1704.

Vrednost denarja okrog leta 1700 lahko ocenimo samo na podlagi primerjav s plačami ter cenami živil in stvari za vsakdanjo rabo. Za odgovor na tovrstna vprašanja so temeljne raziskave Alfreda Francisa Pribrama (1938), Fritza Popelke (1930) in Franza Mensija (1935). Relativno drago, vendar verjetno kakovostno je bilo platno, ki ga je Antonio Bellucci leta 1699 na svojo pest naročil iz Augsburga za 60 goldinarjev, da bi nanj naslikal Brezmadežno za graško cerkev sv. Katarine. Bistveno ugodnejših je bilo osem komolcev platna, ki je bilo leta 1731 dostavljeno za tri slike Franza Ignaza Flurerja v prezbiteriju graške stolnice in plačano s 24 goldinarji.

Zaključimo lahko, da cene, ki so jih okrog leta 1700 plačevali za oltarne in druge oljne slike, niso bile odvisne samo od formata slik in števila upodobljenih oseb, ampak tudi od finančnih zmožnosti naročnika in očitno tudi od kraja namestitve. Slike, namenjene za cerkve pomembnih samostanov ali cerkve $\mathrm{v}$ prestolnici nekdanje Notranje Avstrije, so bile praviloma boljše plačane od tistih za okoliške cerkve in samostane ter za kraje ob meji Notranje Avstrije. Ob tem lahko domnevamo, da so bili veliki in gospodarsko močnejši samostani v Gornji Avstriji pripravljeni za oltarne slike plačati več kakor relativno majhni samostani na Štajerskem. In končno smemo tudi domnevati, da so lahko na Dunaju delujoči slikarji, na primer Frančišek Karel Remb in Antonio Bellucci, zahtevali višja plačila kakor kolegi, ki so delovali v Gradcu. 